\title{
Characteristics and Sources of Single Particles in the Urban Liaocheng of North China during the Heating Period
}

\author{
Aijing Song ${ }^{1}$, Jingjing Meng ${ }^{1 *}$, Ruiwen Zhou ${ }^{1}$, Zheng $\mathrm{Li}^{1}$, Yuanyuan $\mathrm{Li}^{1}$, \\ Min Chen ${ }^{1}$, Zhanfang Hou ${ }^{1}$, Li Yan ${ }^{2 *}$, Yiqiu Wang ${ }^{3}$ \\ ${ }^{1}$ School of Geography and the Environment, Liaocheng University, Liaocheng 252000, China \\ ${ }^{2}$ Chinese Academy for Environmental Planning, Beijing 100012, China \\ ${ }^{3}$ Liaocheng Environmental Information and Monitoring Center, Liaocheng 252000, China
}

\section{ABSTRACT}

Liaocheng represents one of the most serious polluted cities in Northern China. To investigate the impact of residential heating activities on atmospheric particles, the chemical composition, size distribution, and evolution process of single particles collected during the wintertime of 2019 were investigated using a single-particle aerosol mass spectrometer (SPAMS). The results showed that the concentrations of four air pollutants including $\mathrm{PM}_{2.5}, \mathrm{SO}_{2}, \mathrm{NO}_{2}$, and $\mathrm{CO}$ during the heating period were 1.1-1.2 times higher than those before the heating period largely due to the increase of pollutant emissions from coal combustion, while $\mathrm{O}_{3}$ concentration during the heating period decreased by $40.2 \%$. The mass spectra and unscaled size distributions of single particles suggested that the particles had undergone a significant aging process during the whole observation period. The acidity of single particles was calculated by the relative acidity ratio $\left(R_{r a}\right)$, which increased from $36.1 \pm 13.9$ before the heating period to $64.8 \pm 43.9$ during the heating period, implying that the single particles were more acidic and less aged during the heating period, mainly due to the enhanced formation of sulfate and nitrate and the decreased $\mathrm{O}_{3}$ concentration during the heating period. Moreover, $R_{r a}$ decreased from clean days to polluted days before and during the heating period, suggesting that the atmospheric particles in polluted days were less acidic and more aged. The percentage of elemental carbon (EC) particles increased by $13.6 \%$ and $11.5 \%$ from clean days to polluted days before and during the heating period, respectively, suggesting the significant contribution of EC particles to the polluted days. Source identification results showed that single particles before the heating period were mostly derived from secondary inorganic source $(26.5 \%)$ and vehicle exhaust $(21.4 \%)$, whereas those during the heating period were largely from coal combustion (24.0\%) and secondary inorganic source (21.4\%).

\footnotetext{
* Corresponding Authors: Jingjing Meng mengjingjing@Icu.edu.cn Li Yan

yanli@caep.org.cn
}

\section{Publisher:}

Taiwan Association for Aerosol Research

ISSN: $1680-8584$ print

ISSN: 2071-1409 online

(c) Copyright: The Author(s).

This is an open access article distributed under the terms of the Creative Commons Attribution License (CC BY 4.0), which permits unrestricted use, distribution, and reproduction in any medium, provided the original author and source are cited.
Keywords: Size distribution, Online source analysis, Aerosol acidity $\left(R_{r a}\right)$, The heating period, Single particle aerosol mass spectrometer (SPAMS)

\section{INTRODUCTION}

In recent years, severe pollution incidents occurred frequently in northern China during the winter, mainly due to residential heating activities by coal combustion during the heating season, which has raised great public concerns (Liu et al., 2016; Chen et al., 2017; Hong et al., 2018; Hu et al., 2018b; Xu et al., 2018; Luo et al., 2019). It has been reported by the National Bureau of Statistics of China (NBSC, 2016) that China contributed to approximately half of the global annual coal consumption, which emitted a large quantity of air pollutants (e.g., $\mathrm{PM}_{2.5}, \mathrm{SO}_{2}, \mathrm{NO}_{x}$, and $\mathrm{CO}$ ), resulting in severe atmospheric pollution (Zhang et al., 2017a; Zhang et al., 2017d). At the same time, the enhancement of air pollutants has a significant impact on air quality, human health, visibility, and global climate change, which are closely related to the chemical composition and 
size distributions of the single particles (Zhang et al., 2017b; Hu et al., 2018a; An et al., 2019; Meng et al., 2020).

The mass concentration, chemical composition, and size distribution of single particles have been studied extensively using the traditional filter sampling method, which usually requires a long sampling time to enable the thorough reaction of single particles with each other (Cheng et al., 2020). In recent years, single particle aerosol mass spectrometer (SPAMS) has been used to monitor the single-particle aerosol online at a high time resolution (Li et al., 2020; Meng et al., 2021). It not only avoids the disadvantages of the traditional offline analysis method, but also excludes the tedious sample pretreatment processes. In addition, the information of particle size, chemical composition and source resolution of single particles can be obtained quickly by SPAMS (Bi et al., 2015; Ma et al., 2016; Zhang et al., 2018; Peng et al., 2019; Shen et al., 2020).

Many studies have been carried out to investigate the sources and the formation mechanism of $\mathrm{PM}_{2.5}$ during the heating period. For example, Beijing suffered from severe $\mathrm{PM}_{2.5}$ pollution due to the stagnant weather in the heating season of 2016 (Li et al., 2018). Lin et al. (2015) reported that the main sources of PAHs were coal combustion and biomass burning during the heating period. In 2017, the air quality of Beijing had improved significantly through the regional joint prevention and control (Pang et al., 2021). However, air quality was still bad during the heating period in most parts of northern China (e.g., the Harbin-Changchun megalopolis) (Zhao et al., 2020). Both the local pollutant emissions and convective motion of aerosol were considered as key contributors to air pollution in the Harbin-Changchun megalopolis during the heating season (Zhao et al., 2020). Liu et al. (2020) found that secondary inorganic aerosol and coal combustion were the spatial sources of $\mathrm{PM}_{10}$ and $\mathrm{PM}_{2.5}$ during the heating season in Tianjin, China. Although residential coal combustion emissions have been proposed as an especially vital contributor to the haze formation in winter, there still has been little information about the size distribution, mixing state, and aging process of single particles in northern China, especially during the heating season (Li et al., 2020).

Shandong Province, situated in the mid-eastern part of northern China, has become one of the areas suffering from regional haze pollution in China (Meng et al., 2020). Liaocheng City, located in the southwest of Shandong Province, was ranked as the top 32th most polluted city among 365 Chinese cities with the average $\mathrm{PM}_{2.5}$ concentration of $103 \mu \mathrm{g} \mathrm{m}^{-3}$ from October to December in 2019 (https://www.aqistudy.cn/). The regional transport of air pollutants from Liaocheng has a significant effect on the regional atmospheric pollution of Beijing-Tianjin-Hebei region in China (Zhang et al., 2017c). The winter in Liaocheng is harsher and colder than other cities of China, the heating period in Liaocheng lasts from November to March of the next year. In this study, SPAMS was used to conduct the real-time observation of single aerosol particles in Liaocheng during the wintertime, focusing on the chemical composition, size distribution, relative aerosol acidity, and source analysis of single aerosol particles before and during the heating period. In addition, the characteristics and evolution processes of single particles on clean and polluted days were analyzed. The results will provide an important theoretical base for energy control and emission reduction in northern China, especially for the improvement of air quality during the heating period.

\section{METHODS}

\subsection{Field Measurement}

Liaocheng, located in the western part of Shandong province, is regarded as one of the " $2+$ 26" air pollution transmission channel cities in Beijing-Tianjin-Hebei, China. Field observations were conducted at a national air quality monitoring station on the rooftop of a six-story building $\left(36.43^{\circ} \mathrm{N}, 116.01^{\circ} \mathrm{E}\right)$ in Liaocheng University, which is situated in the southeast of Liaocheng City. The sampling site is surrounded by residential areas, main roads and schools without obvious pollution sources and tall buildings. The single particles were analyzed per hour using a singleparticle aerosol mass spectrometer (SPAMS, 0515R Model, Hexin Analytical Instrument Co., Ltd., China). The heating period of Liaocheng during the winter of 2019 began on November 15 and lasted for four months. To investigate the effect of heating period on the chemical composition, size distribution and source of individual particles in the urban atmosphere of northern China during the wintertime, the whole sampling period was divided into "before the heating" (0:00 on 
24 October to 24:00 on 7 November, 2019) and "during the heating" (from 0:00 on 23 November to $24: 00$ on 7 December, 2019). In addition, the hourly mass concentration of meteorological parameters, gaseous pollutants, and $\mathrm{PM}_{2.5}$ was obtained from Environmental Protection Bureau of Liaocheng (http://www.Ichbj.gov.cn).

\subsection{Descriptions of Observational Instruments}

The principle and structure of SPAMS have been described in detail (Li et al., 2011). In short, the aerosol particles will first enter the instrument aerodynamics lens through a metal orifice with a diameter of $0.1 \mathrm{~mm}$ at a flow rate of $75 \mathrm{~mL} \mathrm{~min}$. The accelerated particles are firstly measured and counted by a dual beam $532 \mathrm{~nm}$ laser, and the aerodynamic diameter of each particle is determined via its time of flight. Then, particles are ionized by a $266 \mathrm{~nm}$ ultraviolet pulse laser to produce positive and negative ions. Meanwhile, the ionized ion fragments are detected by bipolar time-of-flight mass spectrometry, which captures the chemical composition and particle diameter of single aerosol synchronously. To ensure the effectiveness and accuracy of the instrument measurement results, polystyrene beads with particle sizes of $0.23,0.51,0.96$ and $1.96 \mu \mathrm{m}$ are used to calibrate the instrument before sampling, and a fitting curve is drawn to ensure the calibration coefficient $R^{2}>0.99$. At the same time, in order to ensure the accuracy of particle size measurement results, the particles will pass through a drying pipe before being detected to reduce the influence of humidity.

\subsection{Data Analysis}

Data analysis was conducted using Matlab 2014b (Math Work Inc., Natick, MA, USA). When the single-particle mass spectra data were imported into Matlab 2014b, the data were first classified through an adaptive resonance theory neural network algorithm (ART-2a). This algorithm can group similar particles into the same class according to the particle mass spectrometry information. Then the CoCo V1.4 package was used to process the size and mass spectra information. In this study, we set up a learning rate of 0.05 , a vigilance factor of 0.7 , and a maximum of 20 iterations. Meanwhile, data from online sources were obtained using the tracer ions method.

\section{RESULTS AND DISCUSSION}

\subsection{Overview of the Observations}

\subsubsection{Variations in air quality and meteorological conditions}

The temporal variations of meteorological parameters, gaseous pollutants (e.g., $\mathrm{SO}_{2}, \mathrm{NO}_{2}, \mathrm{O}_{3}$ and $\mathrm{CO}$ ), $\mathrm{PM}_{2.5}$, and the number counts of total single particles during the whole observation period are shown in Fig. 1. Temperature decreased drastically from $12.6 \pm 4.7^{\circ} \mathrm{C}$ before the heating to $2.7 \pm 4.2^{\circ} \mathrm{C}$ during the heating period, and relative humidity $(\mathrm{RH}, 67.1 \pm 22.4 \%)$ was higher before the heating than that $(58.7 \pm 20.8 \%)$ during the heating period (Table 1$)$. Similarly, solar radiation presented a decreasing trend, with an average of $118.2 \pm 176.8 \mathrm{~W} \mathrm{~m}^{-2}$ before the heating and $78.9 \pm 130.5 \mathrm{~W} \mathrm{~m}^{-2}$ during the heating period, respectively (Table 1). The average wind speed (1.0 $\left.\pm 0.6 \mathrm{~m} \mathrm{~s}^{-1}\right)$ before the heating period was almost equivalent to that $\left(1.2 \pm 0.6 \mathrm{~m} \mathrm{~s}^{-1}\right)$ during the heating period. Wind speed lower than $1.5 \mathrm{~m} \mathrm{~s}^{-1}$ is considered as stagnant air condition (Chen et al., 2018), indicating that the effect of long-distance transport on the atmospheric particles was minor. Therefore, local emissions and subsequent heterogeneous oxidation might play a leading role in the air quality in this area.

$\mathrm{PM}_{2.5}$ concentration $\left(71.9 \pm 42.9 \mu \mathrm{g} \mathrm{m}^{-3}\right)$ during the heating period was 1.2 times higher than that $\left(62.5 \pm 34.3 \mu \mathrm{g} \mathrm{m}^{-3}\right)$ before the heating period, reflecting that the air quality became worse due to the enhancement of pollutant emissions from coal combustion during the heating period. $\mathrm{PM}_{2.5}$ concentration exhibited a pronounced diurnal profile with two rush-hour peaks in the morning (10:00) and in the nighttime (22:00), respectively (Fig. 2). Similarly, the concentrations of $\mathrm{SO}_{2}, \mathrm{NO}_{2}$ and $\mathrm{CO}$ during the heating period were expected to be 1.1-1.2 times higher than those before the heating period (Table 1, Fig. 1), due largely to the increased coal combustion during the heating period. Interestingly, $\mathrm{NO}_{2}$ was correlated robustly with $\mathrm{CO}(r>0.5, p<0.01)$ before and during the heating period, suggesting that both species shared common sources 


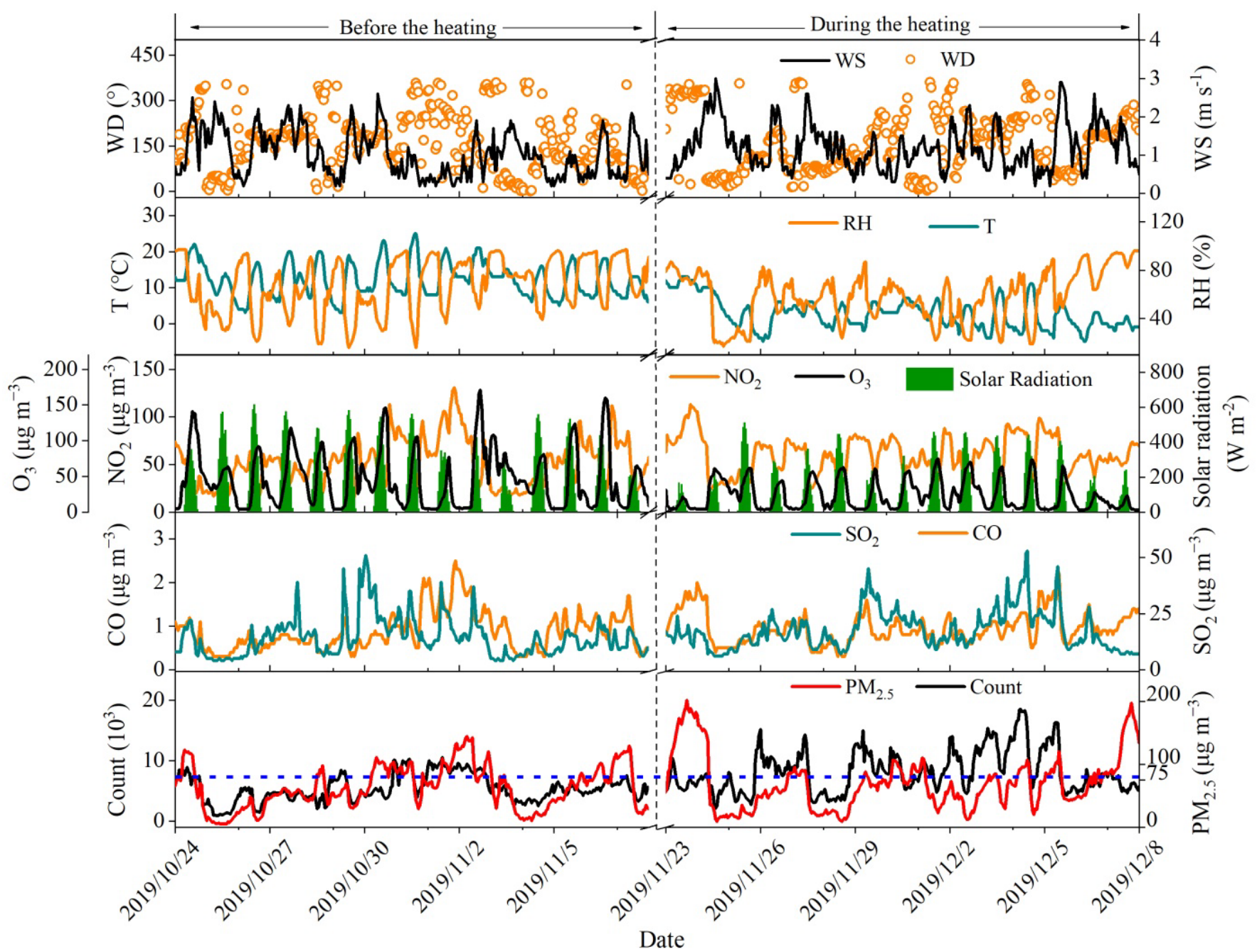

Fig. 1. Temporal variations of meteorological parameters, concentrations of gaseous pollutants, and $\mathrm{PM}_{2.5}$ during the whole observation period.

(e.g., vehicle exhausts). $\mathrm{O}_{3}$ is primarily derived from the photochemical oxidation of $\mathrm{NO}_{x}$ and volatile organic compounds (VOCs), thus it can be used to evaluate the atmospheric oxidation capacity (Meng et al., 2021). Being opposite to the variations of the other four air pollutants, the concentration of $\mathrm{O}_{3}\left(23.2 \pm 20.0 \mu \mathrm{g} \mathrm{m}^{-3}\right)$ during the heating period decreased by $40.2 \%$ compared to that $\left(38.8 \pm 46.7 \mu \mathrm{g} \mathrm{m}^{-3}\right)$ before the heating period, suggesting that the oxidation capacity of atmosphere became weaker during the heating period. The relatively low temperature and weak solar radiation conditions during the heating period limited the formation of $\mathrm{O}_{3}$ (Xu et al., 2020). It has been reported that $\mathrm{O}_{3}$ was negatively correlated with $\mathrm{PM}_{2.5}$ mass concentration because of the impact of aerosol radiative on the photochemistry production of $\mathrm{O}_{3}$ (Wu et al., 2020), thus the higher $\mathrm{PM}_{2.5}$ concentration during the heating period was another significant reason for the reduced $\mathrm{O}_{3}$.

\subsubsection{The characterization of single particles}

A total of 1856200 and 2817180 single particles were collected before and during the heating period, respectively. As shown in Fig. 3, the single particles before and during the heating period had obvious signals of ${ }^{39} \mathrm{~K}^{+}$, carbon ions, ${ }^{23} \mathrm{Na}^{+},{ }^{18} \mathrm{NH}_{4}{ }^{+}$, and $\mathrm{OC}$ fragments (e.g., ${ }^{27} \mathrm{C}_{2} \mathrm{H}_{3}{ }^{+},{ }^{39} \mathrm{C}_{3} \mathrm{H}_{3}{ }^{+}$, ${ }^{41} \mathrm{C}_{3} \mathrm{H}_{5}{ }^{+},{ }^{51} \mathrm{C}_{4} \mathrm{H}_{3}{ }^{+},{ }^{63} \mathrm{C}_{5} \mathrm{H}_{3}{ }^{+}$, and ${ }^{74} \mathrm{C}_{6} \mathrm{H}_{2}{ }^{+}$) in the positive spectra, and the negative spectra were characterized by strong signals of ${ }^{26} \mathrm{CN}^{-},{ }^{42} \mathrm{CNO}^{-}$, and secondary inorganic ions (e.g., ${ }^{46} \mathrm{NO}_{2}{ }^{-}$, ${ }^{62} \mathrm{NO}_{3}{ }^{-},{ }^{80} \mathrm{SO}_{3}{ }^{-}$, and ${ }^{97} \mathrm{HSO}_{4}{ }^{-}$). The signal peaks of $\mathrm{OC}$ fragments were more obvious during the heating period than those before the heating period, but the signal intensities of carbon ions 
Table 1. Concentrations of $\mathrm{PM}_{2.5}$ and gaseous pollutants, meteorological parameters, and count of each type of single particles during the whole observation period.

\begin{tabular}{|c|c|c|c|}
\hline & Before heating & During heating & Whole period \\
\hline $\mathrm{PM}_{2.5}\left(\mu \mathrm{g} \mathrm{m}^{-3}\right)$ & $62.5 \pm 34.3$ & $71.9 \pm 42.9$ & $67.2 \pm 38.8$ \\
\hline Count & 1856200 & 2817180 & 4673380 \\
\hline \multicolumn{4}{|c|}{ Sample classification (number of count) } \\
\hline EC & 709770 & 562870 & 1272640 \\
\hline OC & 301510 & 853340 & 1154850 \\
\hline $\mathrm{ECOC}$ & 88820 & 387290 & 476110 \\
\hline Dust & 174850 & 268940 & 443790 \\
\hline BB & 297600 & 474840 & 772440 \\
\hline $\mathrm{Sec}$ & 184510 & 142490 & 327000 \\
\hline $\mathrm{HM}$ & 99140 & 127410 & 226550 \\
\hline \multicolumn{4}{|l|}{ Meteorological parameters } \\
\hline Temperature $\left({ }^{\circ} \mathrm{C}\right)$ & $12.6 \pm 4.7$ & $2.7 \pm 4.2$ & $7.5 \pm 6.5$ \\
\hline Relative humidity (\%) & $67.1 \pm 22.4$ & $58.7 \pm 20.8$ & $62.9 \pm 22.1$ \\
\hline Wind speed $\left(\mathrm{m} \mathrm{s}^{-1}\right)$ & $1.0 \pm 0.6$ & $1.2 \pm 0.6$ & $1.1 \pm 0.6$ \\
\hline Solar Radiation $\left(\mathrm{W} \mathrm{m}^{-2}\right)$ & $118.2 \pm 176.8$ & $78.9 \pm 130.5$ & $98.6 \pm 156.6$ \\
\hline \multicolumn{4}{|l|}{ Gaseous pollutants } \\
\hline $\mathrm{O}_{3}\left(\mu \mathrm{g} \mathrm{m}^{-3}\right)$ & $38.8 \pm 46.7$ & $23.2 \pm 20.0$ & $34.9 \pm 33.0$ \\
\hline $\mathrm{NO}_{2}\left(\mu \mathrm{g} \mathrm{m}^{-3}\right)$ & $49.2 \pm 25.3$ & $60.1 \pm 19.9$ & $54.6 \pm 23.4$ \\
\hline $\mathrm{SO}_{2}\left(\mu \mathrm{g} \mathrm{m}^{-3}\right)$ & $14.2 \pm 8.6$ & $17.6 \pm 8.5$ & $15.9 \pm 8.7$ \\
\hline $\mathrm{CO}\left(\mu \mathrm{g} \mathrm{m}^{-3}\right)$ & $0.9 \pm 0.4$ & $1.0 \pm 0.4$ & $0.9 \pm 0.4$ \\
\hline
\end{tabular}
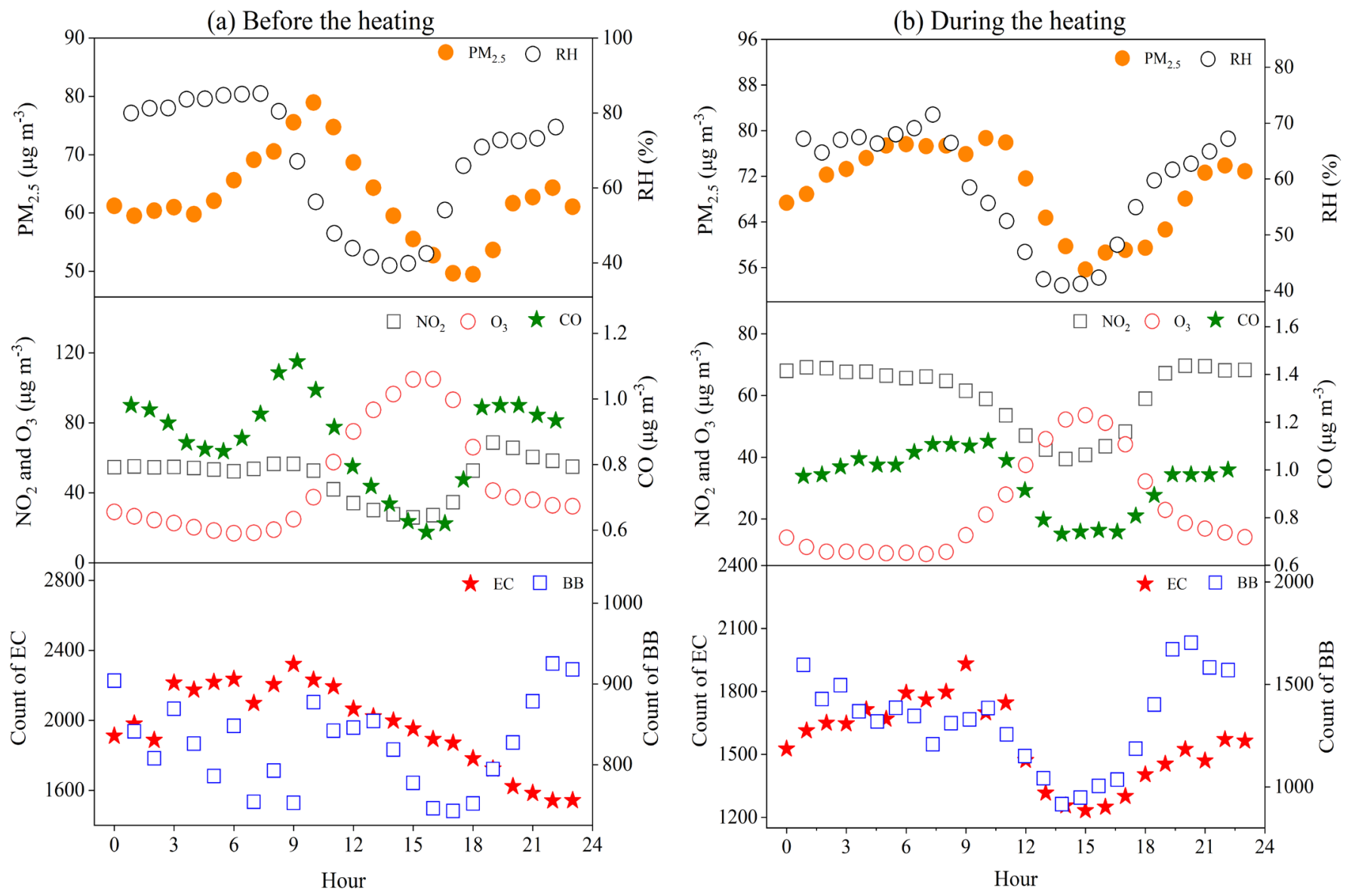

Fig. 2. Hourly variations in $\mathrm{PM}_{2.5}$ and $\mathrm{RH}$, gaseous pollutants $\left(\mathrm{NO}_{2}, \mathrm{O}_{3}\right.$ and $\left.\mathrm{CO}\right), \mathrm{EC}$ and $\mathrm{BB}$ particles (a) before the heating period, and (b) during the heating period. 

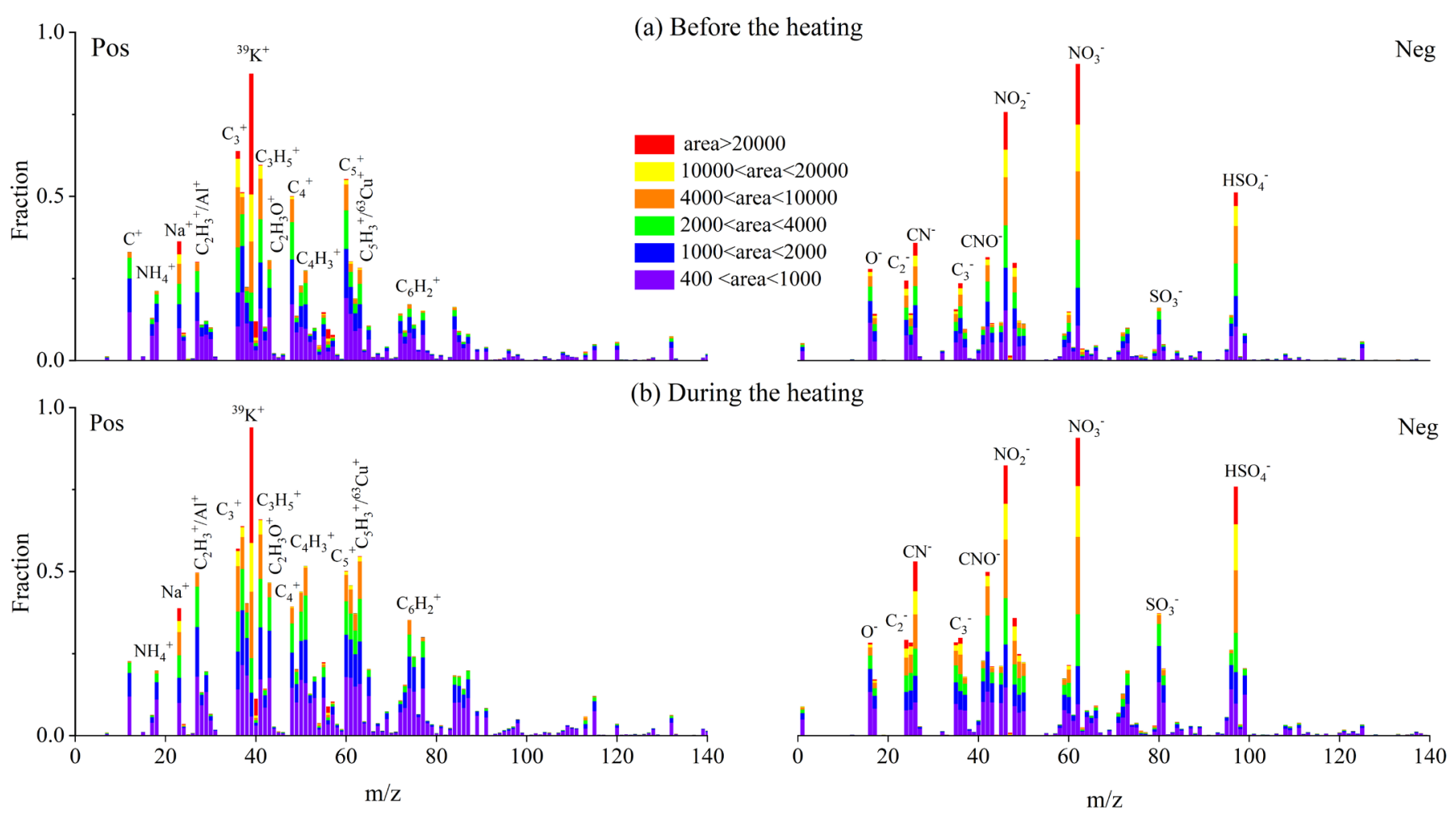

Fig. 3. Mass spectra of detected particles (a) before the heating period, and (b) during the heating period. Color bars represent each peak area corresponding to a specific fraction in individual particles.

were relatively weak. Meanwhile, the proportion of ${ }^{80} \mathrm{SO}_{3}{ }^{-}$and ${ }^{97} \mathrm{HSO}_{4}{ }^{-}$increased during the heating period, indicating that the heterogeneous reaction with $\mathrm{SO}_{2}$ increased to form sulfate (Wang et al., 2019a). Nevertheless, the signals of both ${ }^{46} \mathrm{NO}_{2}{ }^{-}$and ${ }^{62} \mathrm{NO}_{3}{ }^{-}$were stronger than that of ${ }^{97} \mathrm{HSO}_{4}{ }^{-}$both before and during the heating period, which illustrated that the single particles were subject to the formation of nitrate in the aging process. The single particles have been regarded to be aged when the negative mass spectra were dominated by the high abundances of secondary species including ${ }^{46} \mathrm{NO}_{2}{ }^{-},{ }^{62} \mathrm{NO}_{3}{ }^{-}$, and ${ }^{97} \mathrm{HSO}_{4}{ }^{-}$, or more abundant signals of nitrate than sulfate as observed in the same mass spectrum (Meng et al., 2021). As shown in Fig. 3, both the secondary species and the stronger signals of nitrate than sulfate were observed before and during the heating period, indicating that single particles have been suspended in the atmosphere for a long time and undergone a significant aging process during the whole observation period. The single particles before and during the heating period presented unimodal distributions with a peak at a smaller size $(\sim 0.46 \mu \mathrm{m})$ during the heating period than that $(\sim 0.48 \mu \mathrm{m})$ before the heating period, which was attributed to different sources and formation mechanisms (Fig. 4(b)).

\subsection{Characteristics of Major Particles Types}

The single particles were manually classified into seven types by ART-2a according to the characteristics of the respective ion peak, including elemental carbon (EC), organic carbon (OC), EC and OC combined particles (ECOC), dust particles (Dust), biomass burning (BB), secondary (Sec), and heavy metals (HM). The mass spectra of the particle types throughout the entire sampling period are shown in Fig. 5 . In the positive spectrum, the signal peak of ${ }^{39} \mathrm{~K}^{+}$was commonly found in all particle types because of the extreme sensitivity of the SPAMS instrument to $\mathrm{K}^{+}$(Wang et al., 2019b). And the signal peaks of nitrate $(\mathrm{m} / \mathrm{z}-46$ and -62$)$ and sulfate $(\mathrm{m} / \mathrm{z}-97)$ were obvious in the negative spectrum, suggesting that all types of particles experienced different degree of aging. As presented in Table 1 and Fig. 6, the dominant particle type was EC (38.3\%), followed by OC (16.2\%) and BB (16.0\%) before the heating period. However, the contribution of OC $(30.3 \%)$ became the most important during the heating period, while EC $(20.0 \%)$ and biomass burning (16.9\%) were still at high levels. 

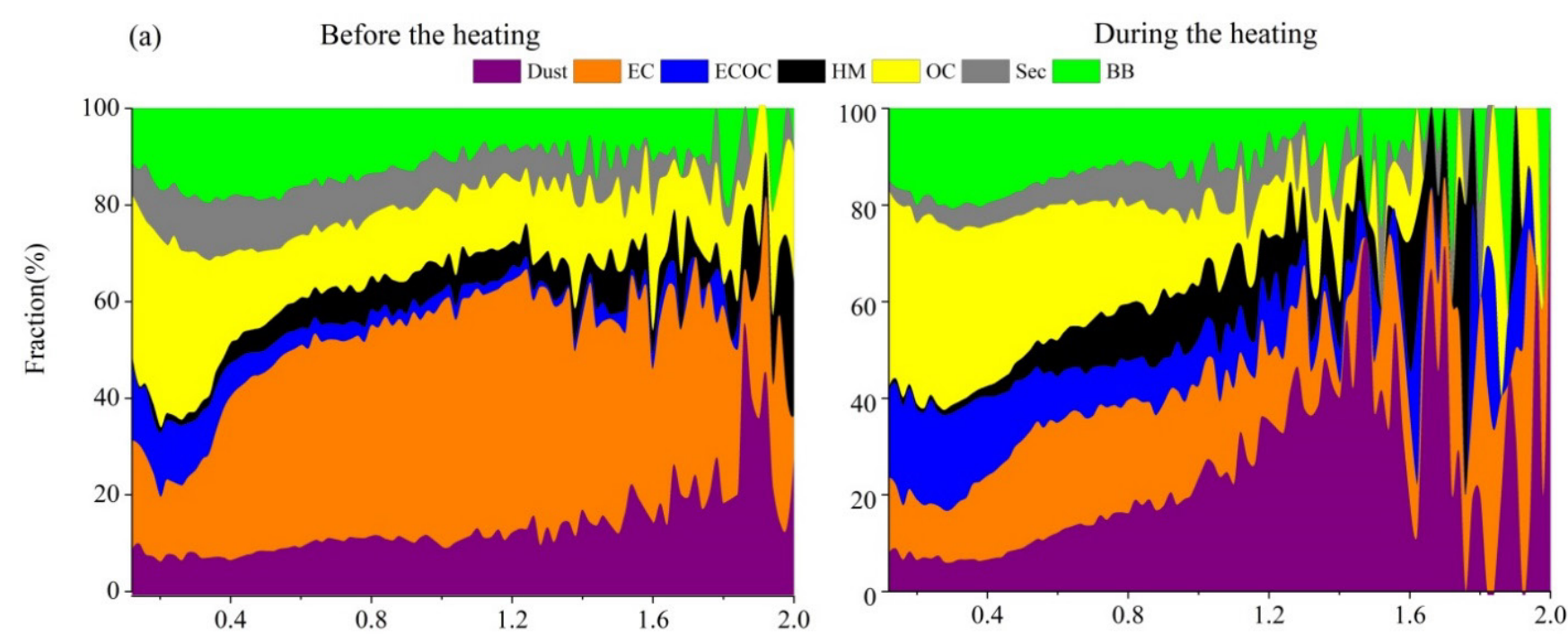

(b)
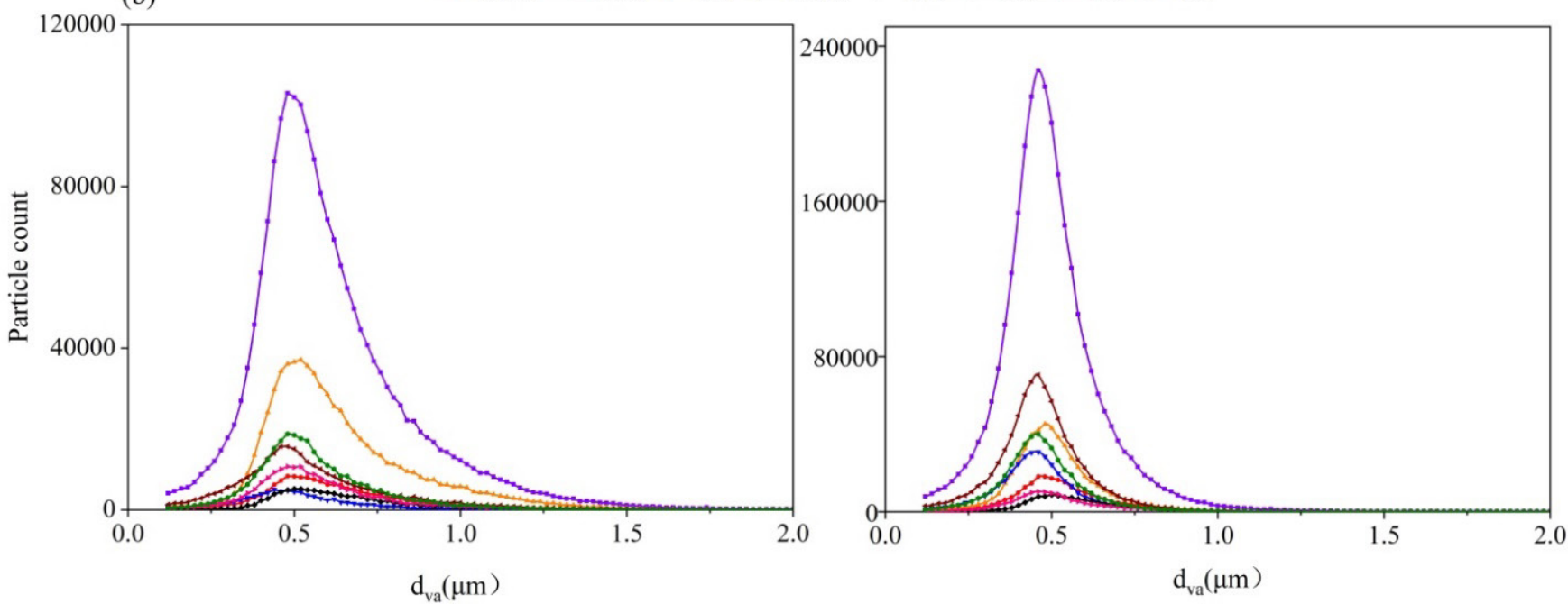

Fig. 4. Unscaled size distributions of single particles before and during the heating period.

\subsubsection{Carbonaceous particles}

Carbonaceous species mainly include three types, including EC, OC, and ECOC particles, whose peaks in the positive spectra did not change significantly before and during the heating period. Three kinds of carbonaceous species in the negative spectra before the heating period were dominated by ${ }^{62} \mathrm{NO}_{3}{ }^{-}$, but these particles during the heating period were pronounced in ${ }^{97} \mathrm{HSO}_{4}{ }^{-}$ except for EC particles (Fig. 5), indicating that carbonaceous particles favored the sulfate formation during the heating period (Shen et al., 2020). EC particles, which are mainly derived directly from the incomplete combustion of fossil and biomass fuels (Lin et al., 2017; Huang et al., 2018), had obvious signals of $\mathrm{C}_{n}^{+/-}(n=1,2, \ldots 6)$ in the positive and negative mass spectra. They showed the similar variations with $\mathrm{CO}$ and peaked at 9:00 during the heating period (Fig. 2), suggesting that they had the common prevenance. The count of EC decreased from 709770 before the heating period to 562870 during the heating period, accounting for $36.3 \%$ and $20.0 \%$ of the total detected particles, respectively. Thus, both the count of EC particles and its percentage contribution to the total particles were higher before the heating period than those during the heating period, mainly owing to the reduction in the direct emissions of primary single particles during the heating period. As listed in Fig. 7, EC particles had a strong correlation $(r=0.77, p<0.01)$ with HM particle before the heating period, implying that they had similar sources before the heating period. However, such a robust correlation was not obtained during the heating period $(r=0.47, p<$ 0.01). 
(a) Before the heating
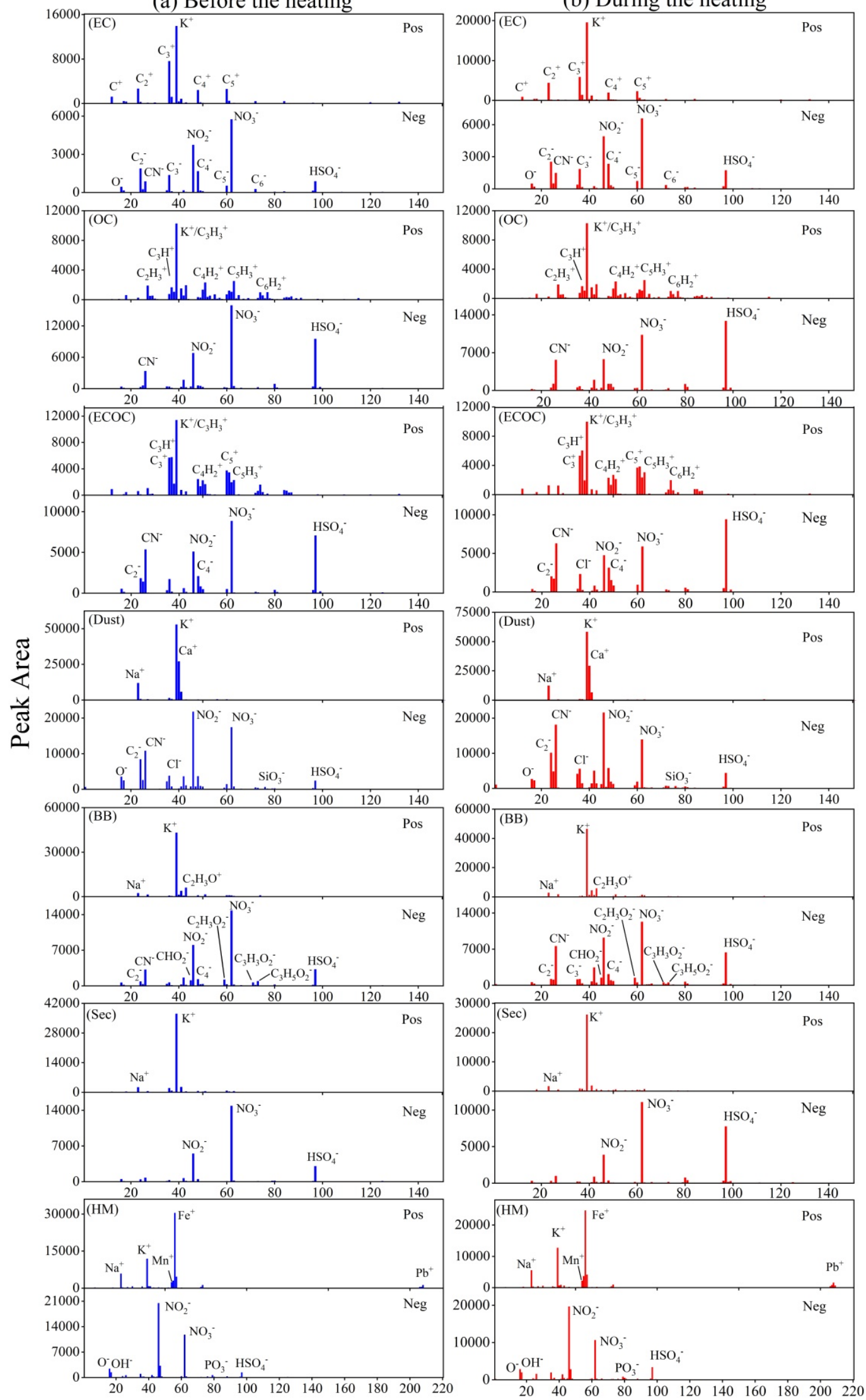

$\mathrm{m} / \mathrm{z}$

(b) During the heating
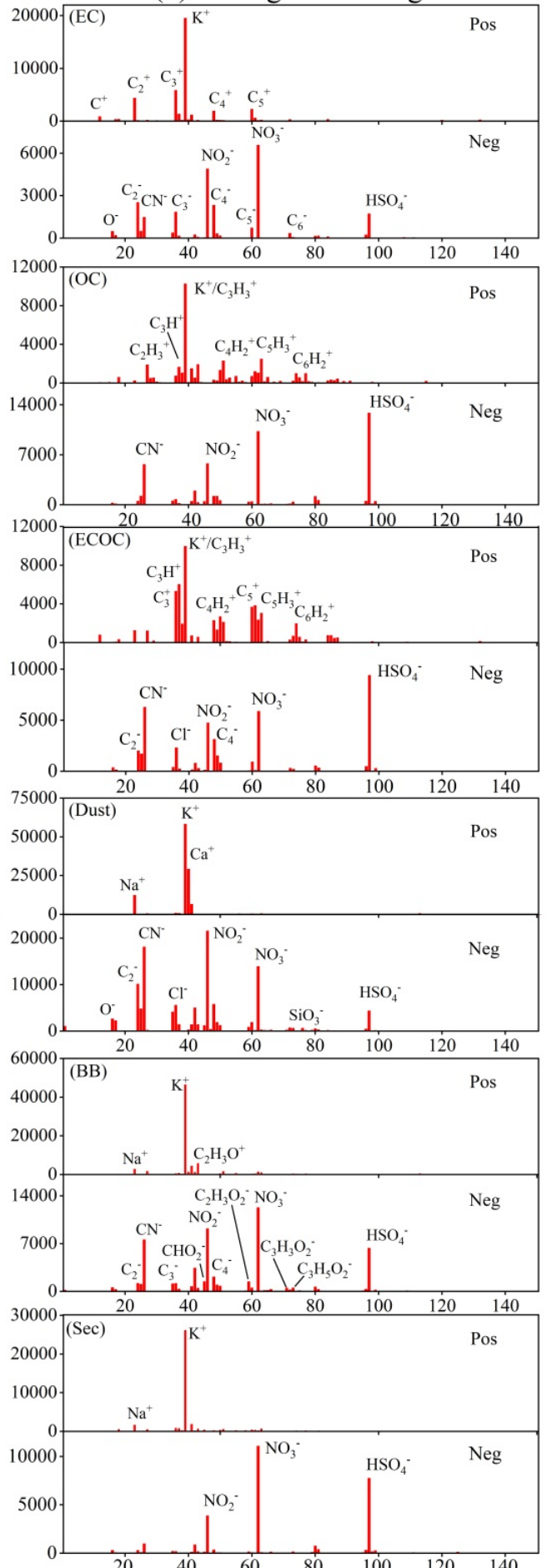

Fig. 5. Average mass spectra of seven types of single particles (a) before the heating period, and (b) during the heating period. 

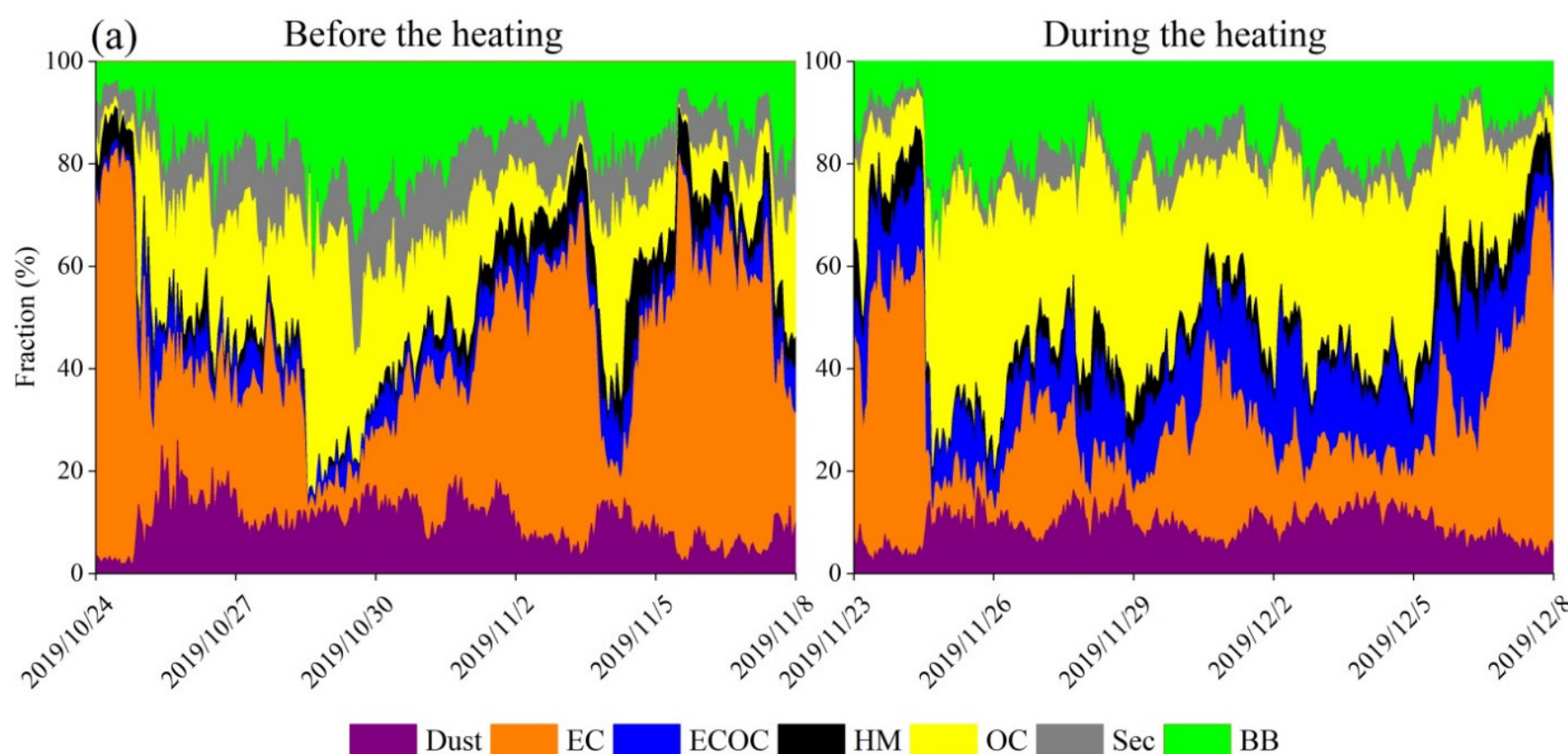

$n^{3}$

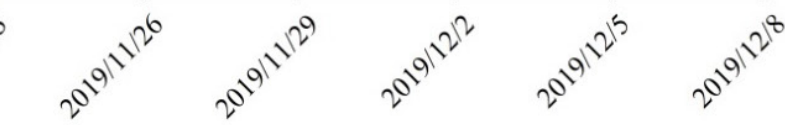

(b)

Before the heating

Clean days
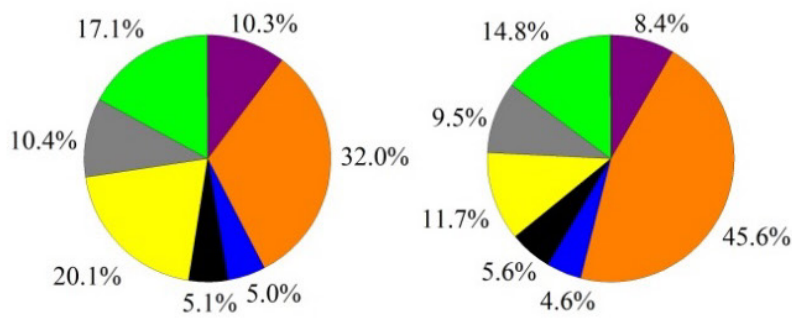

$\mathrm{HM} \quad \mathrm{OC} \quad \mathrm{Sec}$

BB

Fig. 6. (a) Temporal variations in the fractions of each type of single particles; (b) average percentages of single particle types during the four stages: clean days before the heating period, polluted days before the heating period, clean days during the heating period and polluted days during the heating period.

(a) Before the heating

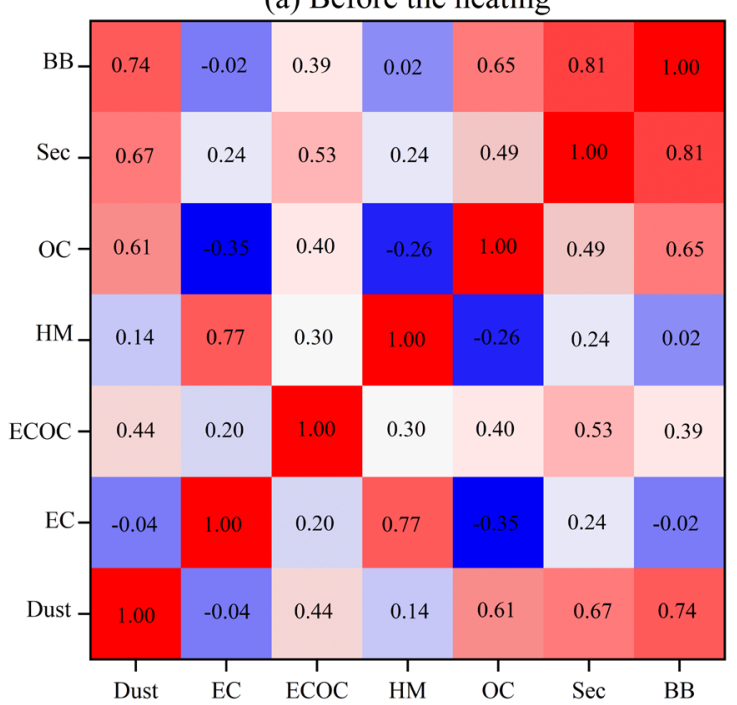

(b) During the heating

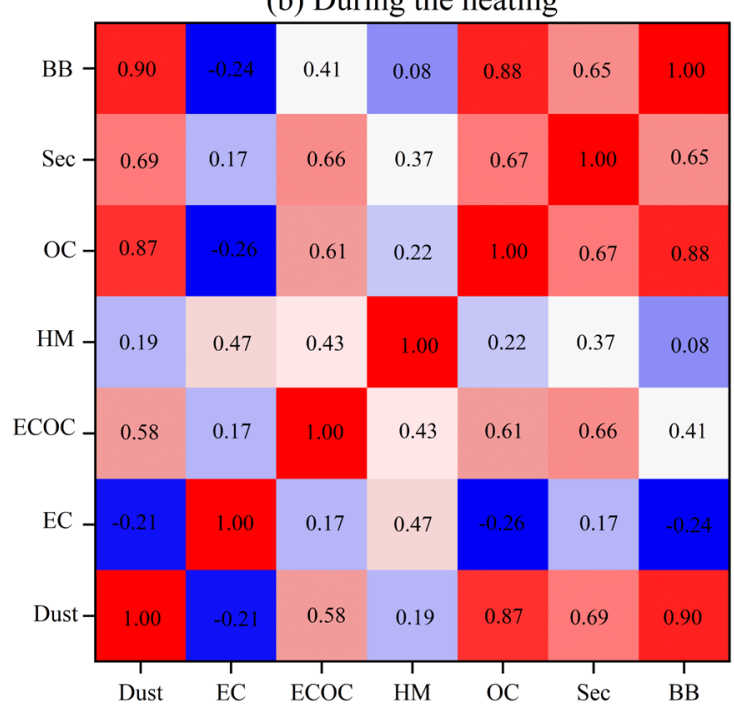

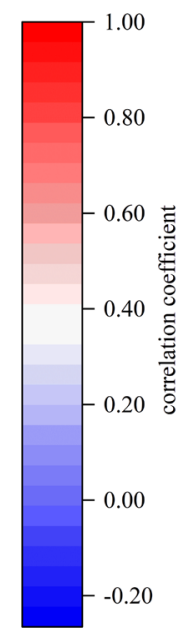

0.20

Fig. 7. Correlation coefficients $(r)$ of single particle types (a) before the heating period, and (b) during the heating period. 
The positive mass spectra of $\mathrm{OC}$ particles presented strong signals of ${ }^{27} \mathrm{C}_{2} \mathrm{H}_{3}{ }^{+},{ }^{37} \mathrm{C}_{3} \mathrm{H}^{+},{ }^{39} \mathrm{C}_{3} \mathrm{H}_{3}{ }^{+}$, ${ }^{50} \mathrm{C}_{4} \mathrm{H}_{2}{ }^{+},{ }^{63} \mathrm{C}_{5} \mathrm{H}_{3}{ }^{+}$, and ${ }^{74} \mathrm{C}_{6} \mathrm{H}_{2}{ }^{+}$. This particle type is typically attributed to the primary combustion such as biomass burning, vehicular emissions, and coal combustion as well as the secondary formation via the atmospheric photochemical reaction of anthropogenic and biogenic volatile organic precursors (Chang et al., 2017; Mao et al., 2018). Being opposite to the variations of EC particles, the number counts of OC particles during the heating (853340) increased by $14.1 \%$ compared to that before the heating (301510) (Table 1). As an indicator for secondary organic species (Meng et al., 2021), oxalic acid $(\mathrm{m} / \mathrm{z}-89)$ showed the stronger signal before the heating period than that during the heating period, largely due to the stronger atmospheric oxidizing capacity $\left(\mathrm{O}_{3}\right.$ concentration), the higher temperature, and the stronger solar radiation conditions before the heating period. In addition, OC particles were correlated strongly with BB particles and dust particles before $(r>0.60, p<0.01)$ and during the heating period $(r>0.86, p<0.01)$, respectively (Fig. 7). And the correlations during the heating period were significantly higher than that before the heating period, suggesting that OC particles were strongly associated with BB particles during the heating period. In addition, traffic dust around the sampling site is an important contributor to the OC particles (Wang et al., 2019b).

ECOC particles, mainly derived from the vehicle emission in urban areas (Liu et al., 2016; Yang et al., 2017), were characterized by $\mathrm{C}_{n}{ }^{ \pm}$and $\mathrm{C}_{\mathrm{n}} \mathrm{H}_{\mathrm{m}}{ }^{+}$in both the positive and negative mass spectra. The signal of sulfate signals was more obvious in the negative spectra during the heating period than that before the heating period, which may be associated with the enhancement of coal combustion (Wang et al., 2019b). Moreover, a total of 387290 ECOC particles were determined during the heating, which was 4.4 times higher than that before the heating (Table 1). And this particle type accounted for $13.7 \%$ of the total particles during the heating period, which increased by $8.9 \%$ compared with that $(4.8 \%)$ before the heating period.

\subsubsection{Dust particles}

Dust particles, mainly derived from construction, re-suspended road dust and natural soil (Luo et al., 2019), were characterized by strong peak of ${ }^{40} \mathrm{Ca}^{+}$and weak peaks of ${ }^{60} \mathrm{SiO}_{2}{ }^{-}$and ${ }^{76} \mathrm{SiO}_{3}{ }^{-}$. Moreover, the stronger peak of nitrate $\left({ }^{46} \mathrm{NO}_{2}{ }^{-}\right.$and $\left.{ }^{62} \mathrm{NO}_{3}{ }^{-}\right)$than that of sulfate $\left({ }^{97} \mathrm{HSO}_{4}{ }^{-}\right)$was observed both before and during the heating period, suggesting that the more dust particles had heterogeneous reactions with $\mathrm{NO} x$ rather than $\mathrm{SO}_{2}$ (Sullivan et al., 2007; Mao et al., 2018). The relative abundance of dust particles in the total detected particles $(9.4 \%)$ before the heating period was equivalent to that (9.5\%) during the heating period. Given that the wind speed in the observation period was less than $2 \mathrm{~m} \mathrm{~s}^{-1}$, dust particles were mainly emitted from road dust (Wang et al., 2019b). In addition, dust particles were correlated well with BB particles before ( $r=$ $0.74, p<0.01)$ and during $(r=0.90, p<0.01)$ the heating period (Fig. 7), respectively, suggesting the significant impact of biomass burning on the dust particles.

\subsubsection{Biomass burning particles}

BB particles showed a representative peak of levoglucosan ion fragments (e.g., ${ }^{45} \mathrm{CHO}_{2}{ }^{-}$, ${ }^{59} \mathrm{C}_{2} \mathrm{H}_{3} \mathrm{O}_{2}{ }^{-},{ }^{71} \mathrm{C}_{3} \mathrm{H}_{3} \mathrm{O}_{2}{ }^{-}$, and ${ }^{73} \mathrm{C}_{3} \mathrm{H}_{5} \mathrm{O}_{2}{ }^{-}$), which are important tracers of biomass burning (Chen et al., 2017; Wu et al., 2018) in the mass spectrum (Fig. 5). In addition, BB particles contained abundant signals of $\mathrm{K}^{+}$and secondary inorganic ions. The signal peak of nitrate was stronger than that of sulfate before and during the heating period, indicating the existence of aged biomass particles. $\mathrm{BB}$ particles started to increase at 5:00 and 7:00 before and during the heating period, respectively, and reached the first peak at 10:00 (Fig. 2). The other peak rose greatly at 18:00 before the heating period and at 17:00 during the heating period, which was attributed to the cooking and heating by biomass burning. Similar to the percentage of dust particles, the proportion of BB before the heating period $(16.0 \%)$ was approximately equal to that $(16.9 \%)$ during the heating period.

\subsubsection{Secondary particles}

As shown in Fig. 5, secondary particles were characterized by the strong intensities of ${ }^{23} \mathrm{Na}^{+},{ }^{39} \mathrm{~K}^{+}$, ${ }^{46} \mathrm{NO}_{2}{ }^{-},{ }^{62} \mathrm{NO}_{3}{ }^{-}$and ${ }^{97} \mathrm{HSO}_{4}{ }^{-}$. The count of secondary particles decreased from 184510 before the heating period to 142490 during the heating period, largely due to the unfavorable meteorological conditions, such as the lower temperature, weaker solar radiation, and weaker atmospheric 
oxidation capacity (Table 1) during the heating period. Secondary particles were strongly correlated with dust particles, ECOC particles, OC particles and BB particles before the heating period $\left(r_{\text {Sec-Dust }}=0.67, r_{\text {Sec-ECOC }}=0.53, r_{\text {Sec-OC }}=0.49, r_{\text {Sec-BB }}=0.81, p<0.01\right)$ and during the heating period ( $\left.r_{\text {Sec-Dust }}=0.69, r_{\text {Sec-ECOC }}=0.66, r_{\text {Sec-OC }}=0.67, r_{\text {Sec-BB }}=0.65, p<0.01\right)$, respectively (Fig. 7$)$, suggesting that these types of particles were mixed with secondary particles as discussed above.

\subsubsection{Heavy metal particles}

HM particles are mainly derived from industrial emissions, coal and oil-fired power plant emissions, fossil fuel combustion, and steel plant processes (Liu et al., 2016). HM particles accounted for only $5.0 \%$ of the total detected particles, indicating the minor contribution of industrial and combustion sources to the atmospheric particles. As shown in Fig. 5, HM particles were characterized by the strong intensity of ${ }^{56} \mathrm{Fe}^{+},{ }^{55} \mathrm{Mn}^{+}$, and ${ }^{206,207,208} \mathrm{~Pb}^{+}$in the positive mass spectrum. The negative mass spectrum was dominated by ${ }^{46} \mathrm{NO}_{2}{ }^{-},{ }^{62} \mathrm{NO}_{3}{ }^{-}$, and ${ }^{97} \mathrm{HSO}_{4}{ }^{-}$. The more abundant signals of nitrate than sulfate was observed during the whole observation period, suggesting that HM particles experienced a significant aging process.

\subsection{Size Distribution}

The size distribution was determined by SPAMS with the size range of $0.2-2.0 \mu \mathrm{m}$. Note that larger particles were seldom detected due to the low detection efficiency of the instrument. The unscaled size distributions of different types of particles are shown in Fig. 4. The number fraction of EC particles peaked at $\sim 0.5 \mu \mathrm{m}$ before and during the heating period. The number fraction of EC particles decreased significantly over the entire size range during the heating period compared to that before the heating period. It has been reported that the EC particles transferred into the larger size during the aging processing, mainly because the oxidized organic species, nitrate, and sulfate were mixed with EC particles (Chen et al., 2018). It is worth noting that the size distribution of EC particles before the heating period became broader than that during the heating period, suggesting that the EC particles underwent more aging process before the heating period. Meanwhile, the number fraction of EC particles ranging from 0.2 to $0.4 \mu \mathrm{m}$ was low, which was detected to be less than $13.3 \%$ of all detected particles throughout the observation period, suggesting the negligible contribution of fresh vehicle exhaust to the EC particles (Li et al., 2020). Simultaneously, OC particles contributed nearly one half of the total particles with the size smaller than $0.5 \mu \mathrm{m}$, and decreased to $\sim 20 \%$ with a larger size $(>0.5 \mu \mathrm{m})$ (Fig. $4(\mathrm{a}))$, suggesting that the contribution of the primary emission was more significant than that of the secondary sources. As shown in Fig. 4, OC particles peaked at $0.46 \mu \mathrm{m}$ in the whole observation period, and their number fraction decreased with the larger particle size before and during the heating period, indicating that the formation mechanism of $\mathrm{OC}$ particles in these two periods was similar. The size distribution of ECOC particles peaked at $0.46 \mu \mathrm{m}$ and $0.44 \mu \mathrm{m}$ before and during the heating period, respectively. The number fraction was higher during the heating period compared to that before the heating period when the size was smaller than $1.0 \mu \mathrm{m}$. In addition, dust particles had a peak at $0.48 \mu \mathrm{m}$ both before and after the heating period, and their size distribution shifted towards the larger size rapidly due to the heterogeneous photochemical reactions during the long-distance transport (Nie et al., 2014). BB particles displayed the same size distribution before and during the heating period, which was mainly attributed to the same forming process or the same sources during these two observation periods. The highest number fraction of HM particles before and during the heating period peaked at 0.52 and $0.50 \mu \mathrm{m}$, respectively.

\subsection{Evolution of Single Particles on Clean and Polluted Days}

To better understand the effect of residential heating supply on the chemical compositions and sources of atmospheric particles, we divided the observation period into four stages: clean days before the heating period $\left(\mathrm{C}_{1}, \mathrm{PM}_{2.5}<75.0 \mu \mathrm{g} \mathrm{m}^{-3}\right)$, polluted days before the heating period $\left(\mathrm{P} 1, \mathrm{PM}_{2.5} \geq 75.0 \mu \mathrm{g} \mathrm{m}^{-3}\right)$, clean days during the heating period $\left(\mathrm{C} 2, \mathrm{PM}_{2.5}<75.0 \mu \mathrm{g} \mathrm{m}^{-3}\right)$ and polluted days during the heating period $\left(\mathrm{P} 2, \mathrm{PM}_{2.5} \geq 75.0 \mu \mathrm{g} \mathrm{m}^{-3}\right.$ ) according to daily $\mathrm{PM}_{2.5}$ concentration. $C 1, P 1, C 2$, and P2 experienced 9.8, 5.3, 9.4, and 5.7 d, with average $P_{2.5}$ concentrations of 41.7, $100.7,42.1$, and $109.5 \mu \mathrm{g} \mathrm{m}^{-3}$, respectively. 


\subsubsection{Chemical compositions}

The fractions of particle type during the different kinds of observation period are shown in Fig. 6. EC particles (38.3\%) were the dominant species, followed by OC (16.2\%) and BB (16.0\%) particles before the heating period, while OC particles $(30.3 \%)$ were the most abundant species, followed by EC $(20.0 \%)$ and BB (16.9\%) particles during the heating period. The contribution of EC particles in polluted days increased by 1.4 and 1.8 times than that in clean days before and during the heating period, respectively, suggesting that primary sources played an important role in the forming of polluted events. In contrast to the variations of EC particles, the percentage of OC particles in polluted days decreased by $41.8 \%$ and $21.6 \%$ than that in clean days before and during the heating period, respectively. Meanwhile, the relative abundance of OC particles in the detected total particles (26.5\%) in P2 was 2.3 times higher than that (11.7\%) in P1. The reduction of EC particles and the increase of OC particles in P2 was mainly attributed to the accumulation of primary contaminants caused by adverse meteorological conditions, as well as the stronger secondary reactions. Similar to OC particles, the contribution of BB particles also showed a decreasing trend from the clean days to the polluted days, but they were still the second or third dominant species in the polluted days, largely because biomass burning is now still widely used for cooking and heating in the rural areas of northern China. ECOC particles accounted for $13.4 \%$ and $14.0 \%$ in $\mathrm{C} 2$ and $\mathrm{P} 2$, which were 2.7 and 3.0 times higher than that in $\mathrm{C} 1$ and $\mathrm{P} 1$, respectively. The proportions of secondary particles slightly decreased from C1 to P1, but they showed an increasing trend from $\mathrm{C} 2$ to $\mathrm{P} 2$, suggesting that the $\mathrm{C} 1$ was enhanced by the adverse meteorological conditions and $\mathrm{C} 2$ was driven by the enhanced secondary oxidation.

\subsubsection{Online source analysis}

Based on the method of tracer ions, the sources of single particles were divided into eight categories: dust, biomass burning, motor vehicle exhaust, coal combustion, industrial processes, secondary inorganic source, cooking, and others (Fig. 8). It is worth noting that coal combustion was the dominant source of the single particles and made up as high as $24.0 \%$ of the total sources during the heating period, which was 2.8 times higher than that (8.6\%) before the heating period, suggesting that the enhancement of coal combustion for heating was the most important contributor to atmospheric particles during the heating period. However, the most significant source before the heating period was the secondary inorganic source, which accounted for $26.5 \%$ of the total sources, primarily because the more favorable meteorological conditions (e.g., including the higher temperature, stronger solar radiation, and atmospheric oxidation capacity) could promote the formation of secondary inorganic species as discussed above. The second highest source of single particles before the heating period was motor vehicle exhaust, accounting for $21.4 \%$ of the total sources, followed by industrial processes $(13.8 \%)$ and dust (11.9\%). However, the second dominant source of single particles during the heating period was the secondary inorganic source, contributing to $21.4 \%$ of the total sources, followed by industrial processes (14.4\%) and motor vehicle exhaust (14.0\%). It is interesting to note that the percentage of motor vehicle exhaust during the heating period decreased by $34.6 \%$ compared to that before the heating period, which was attributed to the restrictions on vehicle driving by the Liaocheng government during the heating period. The relative abundance (20.0\%) of EC particles in detected total particles during the heating period was 1.9 times lower than that $(38.3 \%)$ before the heating period. Moreover, the diurnal variation of motor vehicle exhaust source was similar to the EC particles (Fig. 6(a) and Fig. 8(a)), indicating that the EC particles were originated from the emissions of motor vehicle exhaust. Similarly, the proportions of coal combustion and OC particles presented the similar diurnal variations during the whole observation period, indicating that coal combustion was an important contributor to the OC particles. The secondary inorganic source during the heating period made less contribution $(26.5 \%)$ than that $(21.4 \%)$ before the heating period, again indicating a decreased contribution of secondary inorganic source during the heating period resulting from the weaker atmospheric oxidation capacity and unfavorable meteorological conditions.

As shown in Fig. 8(b), the secondary inorganic source was observed to be the most abundant source in $\mathrm{C} 1, \mathrm{P} 1$, and P2. Moreover, its contribution increased from clean days to polluted days, reflecting that secondary inorganic source contributed significantly to the formation of polluted days. Meanwhile, the contribution of motor vehicle exhaust source also increased by 5.6 and 

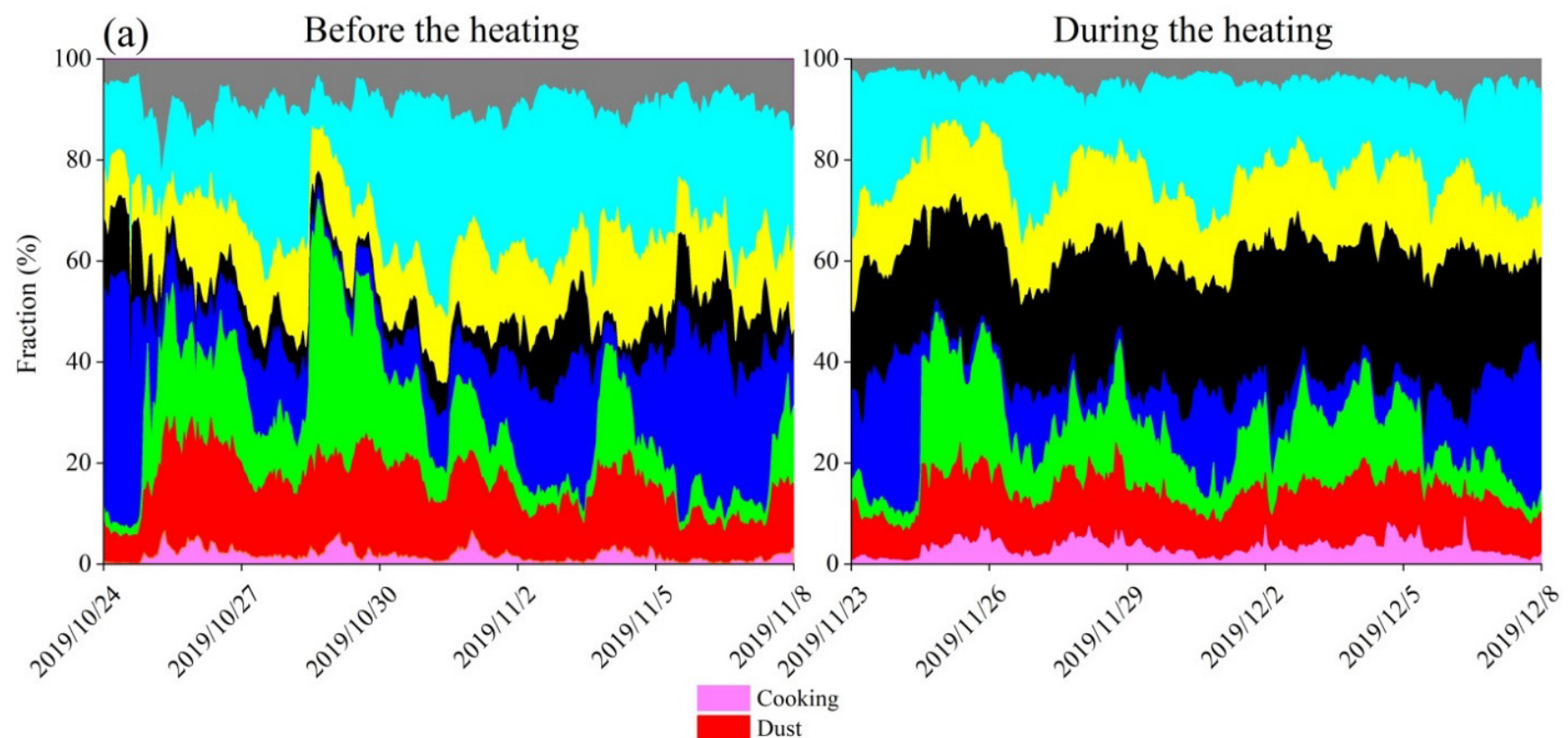

Biomass burning
Motor vehicle exhaust
Coal combustion

(b) Before the heating

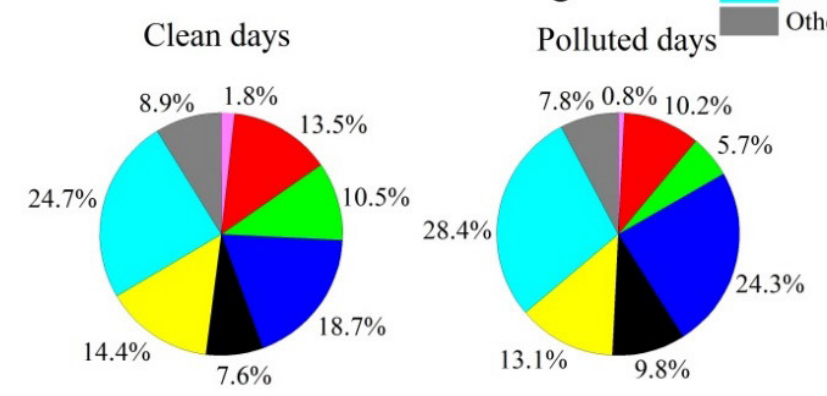

Idustrial processes

Secondary inorganic source During the heating

Clean days $\quad$ Polluted days Others $\quad$ Clean days
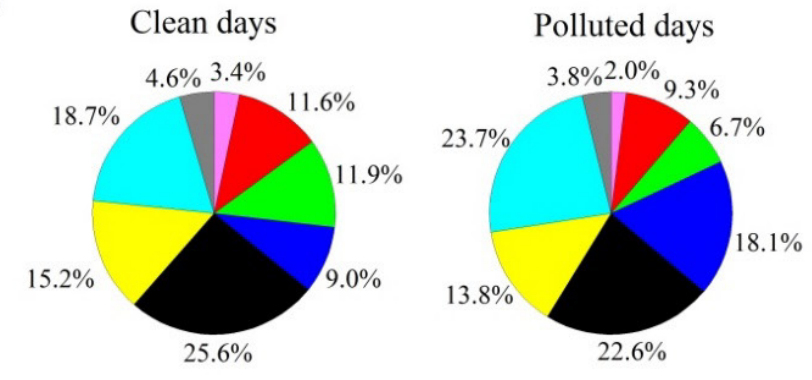

Fig. 8. (a) Temporal variations in the fractions of online sources; (b) average percentages of online sources during the four stages: clean days before the heating period, polluted days before the heating period, clean days during the heating period and polluted days during the heating period.

9.1\% from $\mathrm{C} 1$ to $\mathrm{P} 1$ and from $\mathrm{C} 2$ to $\mathrm{P} 2$, respectively, suggesting that the motor vehicle exhaust source is worthy of attention. In contrast, the fraction of industrial processes, dust, and biomass burning showed a descending trend from clean days to polluted days, again suggesting the minor effect of these polluted sources on the formation of polluted days.

\subsection{Relative Aerosol Acidity}

Aerosol acidity plays an important role in the physical and chemical properties of aerosols (He et al., 2012; Huang et al., 2013). The acidity of the particles cannot be calculated because of the absence of the real-time concentration of inorganic ions in this study. Instead, the relative aerosol acidity $\left(R_{r a}\right)$, defined as the ratio of total peak areas of sulfate and nitrate to that of ammonium, can be used to estimate the acidity of aerosols (Hu et al., 2018a; Meng et al., 2021). Our previous study has obtained a robust correlation $(r=0.85, p<0.01)$ between $R_{r a}$ and in situ particle $\mathrm{pH}$ $\left(\mathrm{pH}_{\mathrm{is}}\right)$ calculated from inorganic ions using the ISORROPIA-II model, confirming the validity of using $R_{r a}$ for evaluating particle acidity (Meng et al., 2021). $R_{r a}$ increased from $36.1 \pm 13.9$ before the heating period to $64.8 \pm 43.9$ during the heating period, implying that the aerosol particles were more acidic during the heating period. Chen et al (2018) has demonstrated that $R_{r a}$ can be used to evaluate aerosol aging. The newly emitted particles are more easily neutralized by the alkalic species as they become aging, thereby resulting in a lower $R_{r a}$ value. As shown in Fig. 9(b), 

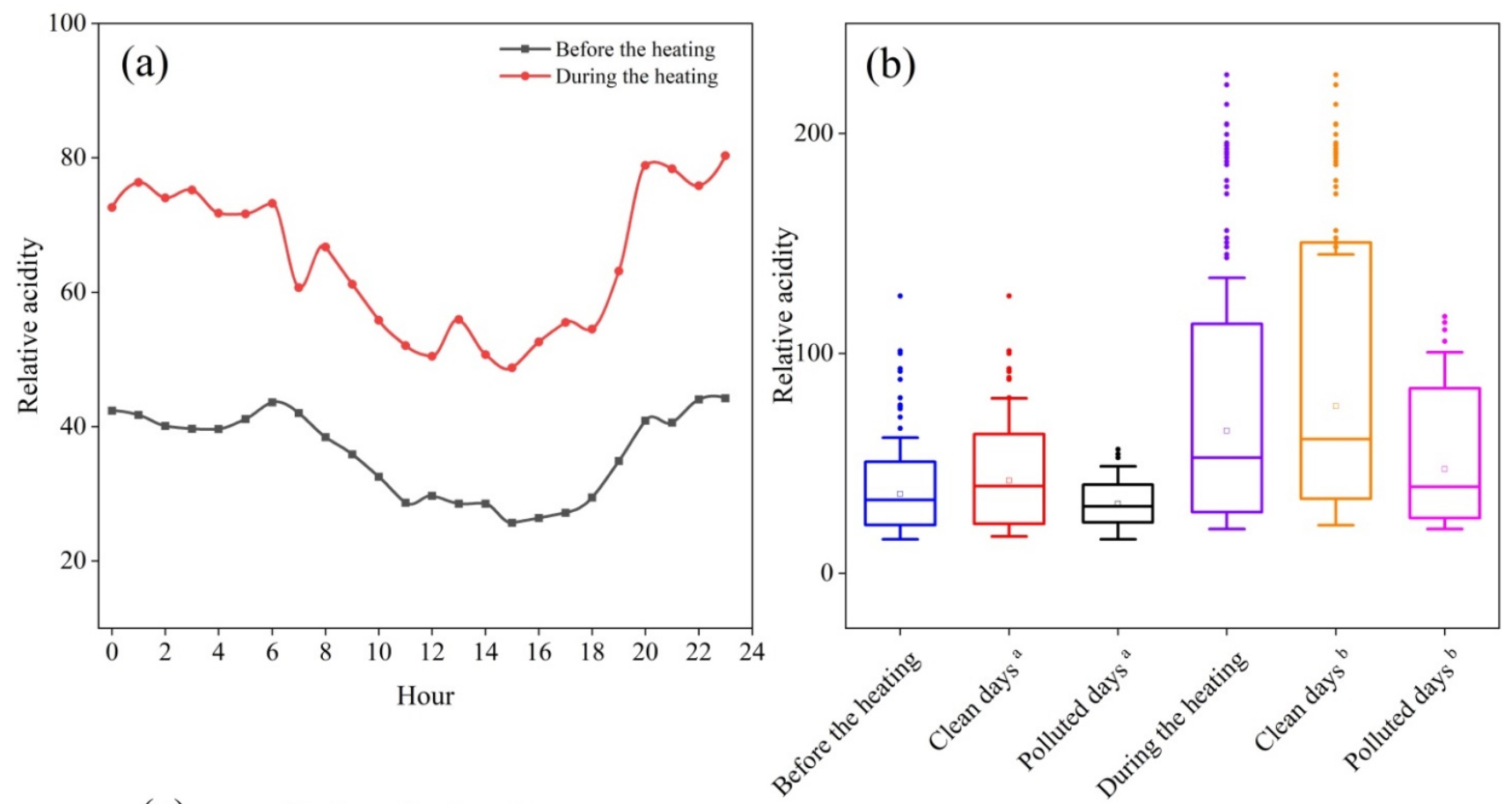

(c) Before the heating
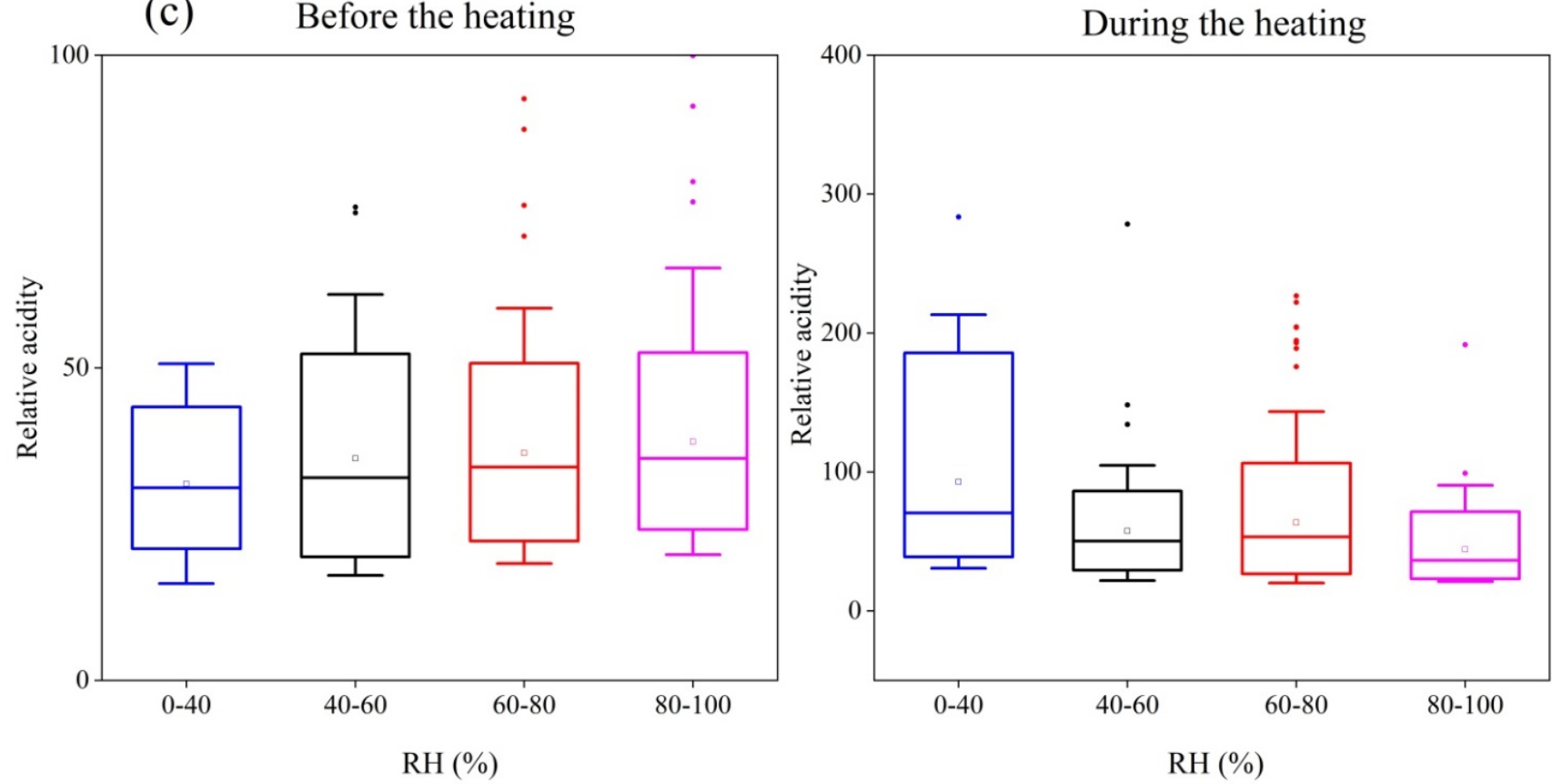

Fig. 9. (a) Hourly variations in relative acidity before and during the heating period; (b) box plot of relative aerosol acidity on different types of day; box plot of relative aerosol acidity as a function of $\mathrm{RH}$ (c) before the heating period, and (d) during the heating period. ( ${ }^{a}$ before the heating; ${ }^{b}$ during the heating)

$R_{r a}$ decreased from clean days to polluted days before and during the heating period, which implied that the atmospheric particles in polluted days were less acidic and more aged. It can be concluded that the fresh particles were more acidic in Liaocheng, which was consistent with field measurements in the urban atmosphere of Xi'an, China (Chen et al., 2018). The diurnal variations of $R_{r a}$ before and during the heating period were illustrated in Fig. 9(a). The smallest $R_{r a}$ was observed at 15:00 during the whole observation period. The acidic gases can react with $\mathrm{NH}_{4} \mathrm{NO}_{3}$ to form $\mathrm{HNO}_{3}$ in the gaseous phase and then uptake ammonium, leading to the decreased $R_{r a}$ (Chen et al., 2018). The highest $R_{r a}$ appeared around 23:00 both before and during the heating period, which was associated with the increased production of $\mathrm{HNO}_{3}$ and $\mathrm{H}_{2} \mathrm{SO}_{4}$ in the aerosol 
Table 2. Peak areas of $\mathrm{SO}_{4}{ }^{2-}, \mathrm{NO}_{3}{ }^{-}$, and $\mathrm{NH}_{4}{ }^{+}$in different range of $\mathrm{RH}$ before and during the heating period.

\begin{tabular}{cllll}
\hline $\mathrm{RH}$ & $0-40 \%$ & $40-60 \%$ & $60-80 \%$ & $80-100 \%$ \\
\hline $\begin{array}{c}\text { Before heating } \\
\mathrm{SO}_{4}{ }^{2-}\end{array}$ & 91403 & 104025 & 126933 & 137149 \\
$\mathrm{NO}_{3}{ }^{-}$ & 3815083 & 5323351 & 5900973 & 7589426 \\
$\mathrm{NH}_{4}{ }^{-}$ & 127198 & 174418 & 180360 & 211987 \\
During heating & & & & \\
$\mathrm{SO}_{4}{ }^{2-}$ & 5506309 & 6790379 & 6844294 & 4220429 \\
$\mathrm{NO}_{3}{ }^{-}$ & 5316773 & 8846695 & 8994814 & 6419335 \\
$\mathrm{NH}_{4}{ }^{-}$ & 164159 & 303234 & 278178 & 241925 \\
\hline
\end{tabular}

droplets at night (Luo et al., 2019). In addition, the value of $R_{r a}$ in nighttime was higher than that in daytime during these two periods, because the diurnal variation of relative acidity was less affected by the heating (Luo et al., 2019).

As shown in Fig. 9, $R_{r a}$ showed a similar diurnal variation with $\mathrm{RH}$, indicating that $\mathrm{RH}$ had a significant effect on the aerosol relative acidity (Zhou et al., 2012). To understand fully the effect of RH on $R_{r a}$, we divided $\mathrm{RH}$ into four parts: $0-40 \%, 40-60 \%, 60-80 \%$ and $80-100 \%$. The absorption of acidic species such as $\mathrm{HSO}_{4}, \mathrm{HNO}_{3}$ and $\mathrm{SO}_{2}$ can be promoted with the increase of water content (Chen et al., 2018), which can lead to a stronger aerosol acidity. Therefore, $R_{r a}$ increased from 31.5 to 38.2 with the increase of $\mathrm{RH}$ before the heating period (Fig. 9(c)), consistent with the larger peaks of nitrate and sulfate (Table 2). Zhang et al. (2021) have reported that the conversion rate of $\mathrm{SO}_{2}$ to $\mathrm{SO}_{4}{ }^{2-}$, and $\mathrm{NO}_{2}$ to $\mathrm{NO}_{3}{ }^{-}$become faster with the increase of $\mathrm{RH}$. We found that the absolute-peak-areas of $\mathrm{SO}_{4}{ }^{2-}$ and $\mathrm{NO}_{3}{ }^{-}$before the heating increased by 45746 and 3774343 with the increase of $\mathrm{RH}$, respectively (Table 2). However, the relationship between $R_{r a}$ and $\mathrm{RH}$ was complicated during the heating period. $R_{r a}$ decreased from 92.9 to 57.5 when $\mathrm{RH}<60 \%$, because the absolute-peak-areas of ammonium (303234) was 1.8 times higher when $\mathrm{RH}$ falling in the range of $40-60 \%$ than that (164159) when $\mathrm{RH}<40 \%$ (Table 2). Although nitrate and sulfate also increased, the increasing amplitude of these two species was smaller than that of ammonium, largely because the enhancement of sulfur oxidation ratios and nitrogen oxidation ratios contributed the creation of atmospheric particulates, especially the transformation of $\mathrm{NH}_{3}$ to $\mathrm{NH}_{4}^{+}$(Zhang et al., 2021). When $\mathrm{RH}>60 \%$, the peak area of $\mathrm{NH}_{4}{ }^{+}$began to decrease, which was attributed to the unchanged gas-particle partitioning ratio of ammonium with the increase of water content when water content was higher than $100 \mu \mathrm{g} \mathrm{m}^{-3}$ (Zhang et al., 2021). When $\mathrm{RH}$ was in a range of $60-80 \%, R_{r a}$ kept increasing up to a mean value of 63.7, which is attributed to the increase of $\mathrm{SO}_{4}{ }^{2-}(6844294)$ and $\mathrm{NO}_{3}{ }^{-}$(8994814) and the decrease of $\mathrm{NH}_{4}{ }^{+}$(278178) (Table 2). Previous studies found that the relative aerosol acidity can increase due to an increase in sulfate produced by the non-catalytic $\mathrm{SO}_{2}$ oxidation in the presence of $\mathrm{NH}_{3}$ when $\mathrm{RH}$ is in the $75-80 \%$ range (Turšič et al., 2004). This implied that the increase in sulfate production was one of the important reasons for the elevating $R_{r a}$ when $\mathrm{RH}$ was in the range of $60-80 \%$. When $\mathrm{RH}>80 \%, R_{r a}$ began to decrease due to the significant reduction of nitrate and sulfate (Table 2 ), which was ascribed to the limit of sulfate production by acidity effect (Wang et al., 2016; Zhang et al., 2021).

\section{CONCLUSIONS}

To fully understand the impact of residential heating activities on the characteristics of atmospheric single particles in the city of Liaocheng, two typical sampling periods (i.e., before the heating, and during the heating) were compared to investigate the difference in chemical compositions, size distributions, and sources of single particles. A total of 1856200 and 2817180 single particles were collected with both positive and negative mass spectrum before and during the heating period, respectively. These single particles were classified into seven types: EC, OC, $\mathrm{ECOC}$, Dust, $\mathrm{BB}, \mathrm{Sec}$, and $\mathrm{HM}$ particles. Compared with those before the heating period, the average concentrations of $\mathrm{PM}_{2.5}, \mathrm{CO}, \mathrm{SO}_{2}$, and $\mathrm{NO}_{2}$ increased during the heating period, while the concentration of $\mathrm{O}_{3}$ decreased, suggesting the weaker oxidation capacity during the heating period. In addition, the signal peaks of OC fragments were more obvious during the heating 
period than those before the heating period, but the signal intensity of carbon ions was weaker. Meanwhile, the proportion of ${ }^{80} \mathrm{SO}_{3}{ }^{-}$and ${ }^{97} \mathrm{HSO}_{4}{ }^{-}$signal peak was higher during the heating period than that before the heating period, indicating an increased heterogeneous reaction with $\mathrm{SO}_{2}$ to form sulfate. EC particles had greater impact on $\mathrm{PM}_{2.5}$ in polluted days, but the fraction of OC particles decreased from clean days to polluted days. The diurnal variation trends of the motor vehicle exhaust source and EC particles proportions were similar, indicating that motor vehicle exhaust contributed significantly to EC particles. The relatively high $R_{r a}$ during the heating period suggested that particle acidity during the heating period was stronger and the aging degree was lower than that before the heating period. The $R_{r a}$ value was closely related to the counts of $\mathrm{H}_{2} \mathrm{SO}_{4}, \mathrm{HNO}_{3}$, and $\mathrm{RH}$, while the effect of heating activities was minor. Source identification results showed that single particles before the heating period were mostly affected by the secondary inorganic source and vehicle exhaust, whereas those during the heating period were influenced by coal combustion and the secondary inorganic source.

\section{ACKNOWLEDGMENTS}

This work was supported by the National Science Foundation of China (Grant Nos. 41505112 and 41702373) and the Natural Science Foundation of Shandong Province (Grant No. ZR2020MD113) and the Open Funds of State Key Laboratory of Loess and Quaternary Geology, Institute of Earth Environment, Chinese Academy of Sciences (Grant No. SKLLQG2020).

\section{REFERENCES}

An, Z., Huang, R. J., Zhang, R., Tie, X., Li, G., Cao, J., Zhou, W., Shi, Z., Han, Y., Gu, Z., Ji, Y. (2019). Severe haze in northern China: A synergy of anthropogenic emissions and atmospheric processes. Proc. Natl. Acad. Sci. U.S.A. 116, 8657-8666. https://doi.org/10.1073/pnas.19001 25116

Bi, X., Dai, S., Zhang, G., Qiu, N., Li, M., Wang, X., Chen, D., Peng, P.., Sheng, G., Fu, J., Zhou, Z. (2015). Real-time and single-particle volatility of elemental carbon-containing particles in the urban area of Pearl River Delta region, China. Atmos. Environ. 118, 194-202. https://doi.org/ 10.1016/j.atmosenv.2015.08.012

Chang, Y., Deng, C., Cao, F., Cao, C., Zou, Z., Liu, S., Lee, X., Li, J., Zhang, G., Zhang, Y. (2017). Assessment of carbonaceous aerosols in Shanghai, China - Part 1: Long-term evolution, seasonal variations, and meteorological effects. Atmos. Chem. Phys. 17, 9945-9964. https://doi.org/10.5194/acp-17-9945-2017

Chen, Y., Wenger, J. C., Yang, F., Cao, J., Huang, R., Shi, G., Zhang, S., Tian, M., Wang, H. (2017). Source characterization of urban particles from meat smoking activities in Chongqing, China using single particle aerosol mass spectrometry. Environ. Pollut. 228, 92-101. https://doi.org/ 10.1016/j.envpol.2017.05.022

Chen, Y., Liu, H., Yang, F., Zhang, S., Li, W., Shi, G., Wang, H., Tian, M., Liu, S., Huang, R., Wang, Q., Wang, P., Cao, J. (2018). Single particle characterization of summertime particles in Xi'an (China). Sci. Total Environ. 636, 1279-1290. https://doi.org/10.1016/j.scitotenv.2018.04.388

Cheng, G., Hu, Y., Sun, M., Chen, Y., Chen, Y., Zong, C., Chen, J., Ge, X. (2020). Characteristics and potential source areas of aliphatic amines in $\mathrm{PM}_{2.5}$ in Yangzhou, China. Atmos. Pollut. Res. 11, 296-302. https://doi.org/10.1016/j.apr.2019.11.002

He, K., Zhao, Q., Ma, Y., Duan, F., Yang, F., Shi, Z., Chen, G. (2012). Spatial and seasonal variability of $\mathrm{PM}_{2.5}$ acidity at two Chinese megacities: Insights into the formation of secondary inorganic aerosols. Atmos. Chem. Phys. 12, 1377-1395. https://doi.org/10.5194/acp-12-1377-2012

Hong, Y., Li, C., Li, X., Ma, Y., Zhang, Y., Zhou, D., Wang, Y., Liu, N., Chang, X. (2018). Analysis of compositional variation and source characteristics of water-soluble ions in $\mathrm{PM}_{2.5}$ during several winter-haze pollution episodes in Shenyang, China. Atmosphere 9, 208. https://doi.org/10.339 0/atmos9070280

Hu, R., Wang, H., Yin, Y., Chen, K., Zhu, B., Zhang, Z., Kang, H., Shen, L. (2018a). Mixing state of ambient aerosols during different fog-haze pollution episodes in the Yangtze River Delta, China. Atmos. Environ. 178, 1-10. https://doi.org/10.1016/j.atmosenv.2018.01.032 
Hu, R., Wang, H., Yin, Y., Zhu, B., Xia, L., Zhang, Z., Chen, K. (2018b). Measurement of ambient aerosols by single particle mass spectrometry in the Yangtze River Delta, China: Seasonal variations, mixing state and meteorological effects. Atmos. Res. 213, 562-575. https://doi.org/ 10.1016/j.atmosres.2018.07.011

Huang, Y., Li, L., Li, J., Wang, X., Chen, H., Chen, J., Yang, X., Gross, D.S., Wang, H., Qiao, L., Chen, C. (2013). A case study of the highly time-resolved evolution of aerosol chemical and optical properties in urban Shanghai, China. Atmos. Chem. Phys. 13, 3931-3944. https://doi.org/10.5 194/acp-13-3931-2013

Huang, Y., Liu, Y., Zhang, L., Peng, C., Yang, F. (2018). Characteristics of carbonaceous aerosol in $\mathrm{PM}_{2.5}$ at Wanzhou in the southwest of China. Atmosphere 9, 37. https://doi.org/10.3390/atmo s9020037

Li, L., Huang, Z., Dong, J., Li, M., Gao, W., Nian, H., Fu, Z., Zhang, G., Bi, X., Cheng, P., Zhou, Z. (2011). Real time bipolar time-of-flight mass spectrometer for analyzing single aerosol particles. Int. J. Mass spectrom. 303, 118-124. https://doi.org/10.1016/j.ijms.2011.01.017

Li, X., Li, S., Xiong, Q., Yang, X., Qi, M., Zhao, W., Wang, X. (2018). Characteristics of PM2.5 chemical compositions and their effect on atmospheric visibility in urban Beijing, China during the heating season. Int. J. Environ. Res. Public Health 15, 1924. https://doi.org/10.3390/ijerph1509 1924

Li, Z., Meng, J., Zhou, L., Zhou, R., Fu, M., Wang, Y., Yi, Y., Song, A., Guo, Q., Hou, Z., Yan, L. (2020). Impact of the COVID-19 event on the characteristics of atmospheric single particle in the northern China. Aerosol Air Qual. Res. 20, 1716-1726. https://doi.org/10.4209/aaqr.2020.06.0321

Lin, Q., Zhang, G., Peng, L., Bi, X., Wang, X., Brechtel, F.J., Li, M., Chen, D., Peng, P., Sheng, G., Zhou, Z. (2017). In situ chemical measurement of individual cloud residue particles at a mountain site, South China. Atmos. Chem. Phys. 17, 8473-8488. https://doi.org/10.5194/acp-2017-23

Lin, Y., Ma, Y., Qiu, X., Li, R., Fang, Y., Wang, J., Zhu, Y., Hu, D. (2015). Sources, transformation, and health implications of PAHs and their nitrated, hydroxylated, and oxygenated derivatives in $\mathrm{PM}_{2.5}$ in Beijing. J. Geophys. Res. 120, 7219-7228. https://doi.org/10.1002/2015jd023628

Liu, B., Sun, X., Zhang, J., Bi, X., Li, Y., Li, L., Dong, H., Xiao, Z., Zhang, Y., Feng, Y. (2020). Characterization and spatial source apportionments of ambient $\mathrm{PM}_{10}$ and $\mathrm{PM}_{2.5}$ during the heating period in Tian'jin, China. Aerosol Air Qual. Res. 20, 1-13. https://doi.org/10.4209/aaq r.2019.06.0281

Liu, L., Wang, Y., Du, S., Zhang, W., Hou, L., Vedal, S., Han, B., Yang, W., Chen, M., Bai, Z. (2016). Characteristics of atmospheric single particles during haze periods in a typical urban area of Beijing: A case study in October, 2014. J. Environ. Sci. 40, 145-153. https://doi.org/10.1016/j.j es.2015.10.027

Luo, J., Huang, X., Zhang, J., Luo, B., Zhang, W., Song, H. (2019). Characterization of aerosol particles during the most polluted season (winter) in urban Chengdu (China) by single-particle analysis. Environ. Sci. Pollut. Res. 26, 17685-17695. https://doi.org/10.1007/s11356-01905156-4

Ma, L., Li, M., Zhang, H., Li, L., Huang, Z., Gao, W., Chen, D., Fu, Z., Nian, H., Zou, L., Gao, J., Chai, F., Zhou, Z. (2016). Comparative analysis of chemical composition and sources of aerosol particles in urban Beijing during clear, hazy, and dusty days using single particle aerosol mass spectrometry. J. Clean Prod. 112, 1319-1329. https://doi.org/10.1016/j.jclepro.2015.04.054

Mao, J., Chen, Z., Mo, Z., Yang, X., Li, H., Liu, Y., Liu, H., Huang, J., Yang, J., Li, H. (2018). Highly time-resolved aerosol characteristics during springtime in Weizhou Island. J. Environ. Sci. 72, 64-74. https://doi.org/10.1016/j.jes.2017.12.012

Meng, J., Liu, X., Hou, Z., Yi, Y., Yan, L., Li, Z., Cao, J., Li, J., Wang, G. (2020). Molecular characteristics and stable carbon isotope compositions of dicarboxylic acids and related compounds in the urban atmosphere of the North China Plain: Implications for aqueous phase formation of SOA during the haze periods. Sci. Total Environ. 705, 135256. https://doi.org/10.1016/j.scitotenv.20 19.135256

Meng, J., Li, Z., Zhou, R., Chen, M., Li, Y., Yi, Y., Ding, Z., Li, H., Yan, L., Hou, Z., Wang, G. (2021). Enhanced photochemical formation of secondary organic aerosols during the COVID-19 lockdown in Northern China. Sci. Total Environ. 758, 143709. https://doi.org/10.1016/j.scitote nv.2020.143709

Nie, W., Ding, A., Wang, T., Kerminen, V.M., George, C., Xue, L., Wang, W., Zhang, Q., Petäjä, T., Qi, 
X., Gao, X., Wang, X., Yang, X., Fu, C., Kulmala, M. (2014). Polluted dust promotes new particle formation and growth. Sci. Rep. 4, 6634. https://doi.org/10.1038/srep06634

Pang, N., Gao, J., Zhu, G., Hui, L., Zhao, P., Xu, Z., Tang, W., Chai, F. (2021). Impact of clean air action on the $\mathrm{PM}_{2.5}$ pollution in Beijing, China: Insights gained from two heating seasons measurements. Chemosphere 263, 127991. https://doi.org/10.1016/j.chemosphere.2020.127991

Peng, X., Liu, X., Shi, X., Shi, G., Li, M., Liu, J., Huangfu, Y., Xu, H., Ma, R., Wang, W., Feng, Y. (2019). Source apportionment using receptor model based on aerosol mass spectra and $1 \mathrm{~h}$ resolution chemical dataset in Tianjin, China. Atmos. Environ. 198, 387-397. https://doi.org/10.1016/j.at mosenv.2018.11.018

Shen, L., Hao, F., Gao, M., Wang, H., Zhu, B., Gao, J., Cheng, Y., Xie, F. (2020). Real-time geochemistry of urban aerosol during a heavy dust episode by single-particle aerosol mass spectrometer: Spatio-temporal variability, mixing state and spectral distribution. Particuology 53, 197-207. https://doi.org/10.1016/j.partic.2020.02.001

Sullivan, R.C., Guazzotti, S.A., Sodeman, D.A., Prather, K.A. (2007). Direct observations of the atmospheric processing of Asian mineral dust. Atmos. Chem. Phys. 7, 1213-1236. https://doi.org/10.5194/acp-7-1213-2007

Turšič, J., Berner, A., Podkrajšek, B., Grgić, I. (2004). Influence of ammonia on sulfate formation under haze conditions. Atmos. Environ. 38, 2789-2795. https://doi.org/10.1016/j.atmosenv.2 004.02.036

Wang, G., Zhang, R., Gomez, M.E., Yang, L., Levy Zamora, M., Hu, M., Lin, Y., Peng, J., Guo, S., Meng, J., Li, J., Cheng, C., Hu, T., Ren, Y., Wang, Yuesi, Gao, J., Cao, J., An, Z., Zhou, W., Li, G., et al. (2016). Persistent sulfate formation from London Fog to Chinese haze. Proc. Natl. Acad. Sci. U.S.A. 113, 13630-13635. https://doi.org/10.1073/pnas.1616540113

Wang, H., Shen, L., Yin, Y., Chen, K., Chen, J., Wang, Y. (2019a). Characteristics and mixing state of aerosol at the summit of Mount Tai $(1534 \mathrm{~m})$ in Central East China: First measurements with SPAMS. Atmos. Environ. 213, 273-284. https://doi.org/10.1016/j.atmosenv.2019.06.021

Wang, S., He, B., Yuan, M., Su, F., Yin, S., Yan, Q., Jiang, N., Zhang, R., Tang, X. (2019b). Characterization of individual particles and meteorological conditions during the cold season in Zhengzhou using a single particle aerosol mass spectrometer. Atmos. Res. 219, 13-23. https://doi.org/10.1016/j.atmosres.2018.12.021

Wu, J., Bei, N., Hu, B., Liu, S., Wang, Y., Shen, Z., Li, X., Liu, L., Wang, R., Liu, Z., Cao, J., Tie, X., Molina, L.T., Li, G. (2020). Aerosol-photolysis interaction reduces particulate matter during wintertime haze events. Proc. Natl. Acad. Sci. U.S.A. 117, 9755-9761. https://doi.org/10.1073/ pnas.1916775117

Wu, K., Duan, M., Liu, H., Zhou, Z., Deng, Y., Song, D., Tan, Q. (2018). Characterizing the composition and evolution of firework-related components in air aerosols during the Spring Festival. Environ. Geochem. Health 40, 2761-2771. https://doi.org/10.1007/s10653-018-0141-9

Xu, J., Wang, H., Li, X., Li, Y., Wen, J., Zhang, J., Shi, X., Li, M., Wang, W., Shi, G., Feng, Y. (2018). Refined source apportionment of coal combustion sources by using single particle mass spectrometry. Sci. Total Environ. 627, 633-646. https://doi.org/10.1016/j.scitotenv.2018.01.269

Xu, K., Cui, K., Young, L.H., Wang, Y.F., Hsieh, Y.K., Wan, S., Zhang, J. (2020). Air quality index, indicatory air pollutants and impact of COVID-19 event on the air quality near central China. Aerosol Air Qual. Res. 20, 1204-1221. https://doi.org/10.4209/aaqr.2020.04.0139

Yang, J., Ma, S., Gao, B., Li, X., Zhang, Y., Cai, J., Li, M., Yao, L., Huang, B., Zheng, M. (2017). Single particle mass spectral signatures from vehicle exhaust particles and the source apportionment of on-line $\mathrm{PM}_{2.5}$ by single particle aerosol mass spectrometry. Sci. Total Environ. 593-594, 310318. https://doi.org/10.1016/j.scitotenv.2017.03.099

Zhang, J., Liu, L., Wang, Y., Ren, Y., Wang, X., Shi, Z., Zhang, D., Che, H., Zhao, H., Liu, Y., Niu, H., Chen, J., Zhang, X., Lingaswamy, A. P., Wang, Z., Li, W. (2017a). Chemical composition, source, and process of urban aerosols during winter haze formation in Northeast China. Environ. Pollut. 231, 357-366. https://doi.org/10.1016/j.envpol.2017.07.102

Zhang, J., Luo, B., Zhang, J., Ouyang, F., Song, H., Liu, P., Cao, P., Schäfer, K., Wang, S., Huang, X. Lin, Y. (2017b). Analysis of the characteristics of single atmospheric particles in Chengdu using single particle mass spectrometry. Atmos. Environ. 157, 91-100. https://doi.org/10.1016/j.atm osenv.2017.03.012

Zhang, J., Yang, L., Chen, J., Mellouki, A., Jiang, P., Gao, Y., Li, Y., Yang, Y., Wang, W. (2017c). 
Influence of fireworks displays on the chemical characteristics of $\mathrm{PM}_{2.5}$ in rural and suburban areas in Central and East China. Sci. Total Environ. 578, 476-484. https://doi.org/10.1016/j.sci totenv.2016.10.212

Zhang, J., Huang, X., Wang, Y., Luo, B., Zhang, J., Song, H., Zhang, W., Liu, P., Schäfer, K., Wang, S. Luo, J., Wu, P. (2018). Characterization, mixing state, and evolution of single particles in a megacity of Sichuan Basin, southwest China. Atmos. Res. 209, 179-187. https://doi.org/10.10 16/j.atmosres.2018.03.014

Zhang, T., Shen, Z.X., Su, H., Liu, S.X., Zhou, J.M., Zhao, Z.Z., Wang, Q.Y., Prévôt, A.S.H.,Cao, J.J. (2021). Effects of aerosol water content on the formation of secondary inorganic aerosol during a winter heavy $\mathrm{PM}_{2.5}$ pollution episode in Xi'an, China. Atmos. Environ. 252, 118304. https://doi.org/10.1016/j.atmosenv.2021.118304

Zhang, Z., Wang, W., Cheng, M., Liu, S., Xu, J., He, Y., Meng, F. (2017d). The contribution of residential coal combustion to $\mathrm{PM}_{2.5}$ pollution over China's Beijing-Tianjin-Hebei region in winter. Atmos. Environ. 159, 147-161. https://doi.org/10.1016/j.atmosenv.2017.03.054

Zhao, X., Zhao, X., Liu, P., Ye, C., Xue, C., Zhang, C., Zhang, Y., Liu, C., Liu, J., Chen, H., Chen, J., Mu, $Y$. (2020). Pollution levels, composition characteristics and sources of atmospheric $\mathrm{PM}_{2.5}$ in a rural area of the North China Plain during winter. J. Environ. Sci. 95, 172-182. https://doi.org/ 10.1016/j.jes.2020.03.053

Zhou, Y., Xue, L., Wang, T., Gao, X., Wang, Z., Wang, X., Zhang, J., Zhang, Q., Wang, W. (2012). Characterization of aerosol acidity at a high mountain site in central eastern China. Atmos. Environ. 51, 11-20. https://doi.org/10.1016/j.atmosenv.2012.01.061 